\title{
TÉCNICAS ERICKSONIANAS PARA LA ELICITACIÓN DEL CONOCIMIENTO JUDICIAL EN UN PROYECTO DE INTELIGENCIA ARTIFICIAL APLICADA AL DERECHO
}

\section{ENRIQUe CÁCERES NIETO}


TÉCNICAS ERICKSONIANAS PARA LA ELICITACIÓN DEL CONOGIMIENTO JUDICIAL EN UN PROYEGTO DE INTELIGENCIA ARTIFICIAL APLICADA AL DERECHO 


\title{
INSTITUTO DE INVESTIGAGIONES JURÍDICAS \\ Serie Publicaciones electrónicas, núm. 15
}

\section{COORDINACIÓN EDITORIAL}

\author{
Lic. Raúl Márquez Romero \\ Secretario Técnico
}

Lic. Wendy Vanesa Rocha Cacho

Jefa del Departamento de Publicaciones

María Teresa de Jesús Baena Sánchez

Diana Luján Verón

Cuidado de la edición

Javier Mendoza Villegas

Formación en computadora

Carlos Martín Aguilera Ortiz

Elaboración de portada 
ENRIQUE CÁGERES NIETO
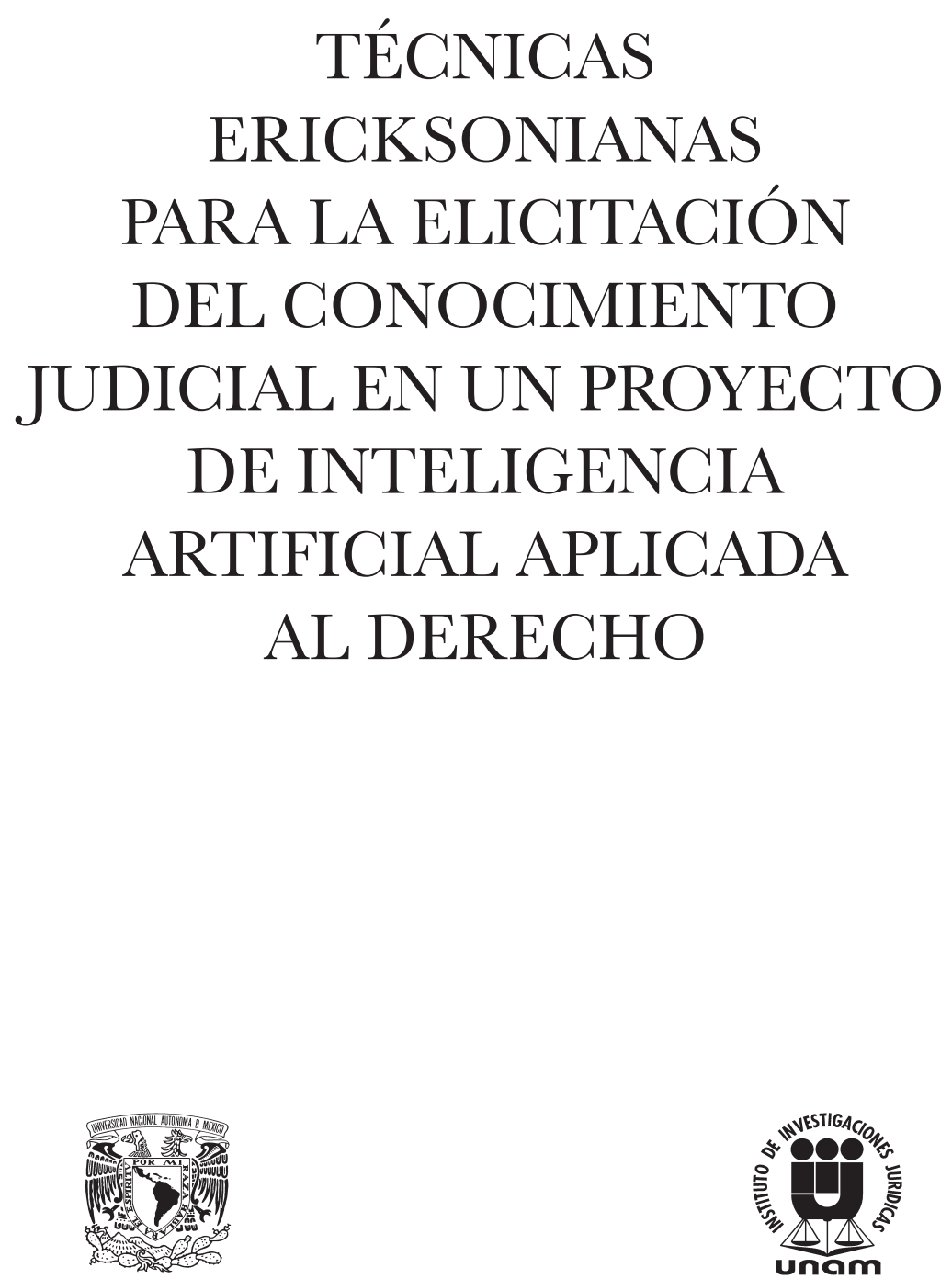

UNIVERSIDAD NACIONAL AUTÓNOMA DE MÉXICO INSTITUTO DE INVESTIGACIONES JURÍDICAS MÉXICO, 2016 
Primera edición: 7 de noviembre de 2016

DR (C) 2016. Universidad Nacional Autónoma de México INSTITUTO DE INVESTIGACIONES JURÍDICAS

Circuito Maestro Mario de la Cueva s/n Ciudad de la Investigación en Humanidades Ciudad Universitaria, 04510 Ciudad de México

Impreso y hecho en México

ISBN 978-607-02-8658-2 


\section{CONTENIDO}

CAPÍtULLO PRIMERO

ANTECEDENTES. . . . . . . . . . . . . . . . . 1

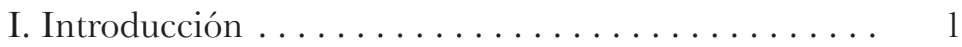

II. Erickson y el derecho. ................ 3

III. Constructivismo ericksoniano y constructivismo jurídico 9

1. La revolución constructivista en la historia de la epis-

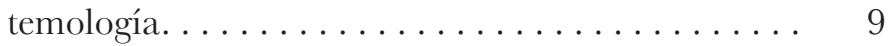

2. Caracterización general de la epistemología constructivista en el ámbito de la ciencia . . . . . . . . . . 13

3. Epistemología constructivista y realidad cotidiana . 14

4. Constructivismo ericksoniano . . . . . . . . . 15

5. Constructivismo jurídico . . . . . . . . . . 17

A. El constructivismo jurídico en el contexto de la historia de la filosofía del derecho22 . . . . . 17

B. Marco conceptual básico del constructivismo ju-

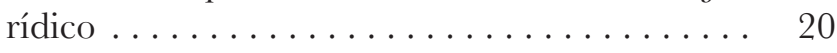

IV. Inteligencia artificial y derecho . . . . . . . . . . . 28

1. Breve introducción a la inteligencia artificial aplicada al derecho. . . . . . . . . . . . . . 28

2. El Proyecto Conacyt 42163-S "Sistemas expertos para la ayuda a la decisión judicial" . . . . . . . . . 
CAPÍtulo Segundo

MARCO TEÓRICO ... . . . . . . . . . . . . . . . . . . 35

I. Técnicas ericksonianas para la elicitación del conocimiento judicial compilado. . . . . . . . . . .

1. Noción de "conocimiento compilado" en ingeniería del conocimiento. . . . . . . . . . . . . . . . 35

2. El conocimiento compilado como teoría implícita . 36

A. Presupuestos de la investigación.......... 41

B. Inducción y problemas no-definidos (el modelo de Holland, Holyoak y Nisbett) . . . . . . . . . . 44

C. Tipos de conocimiento dentro del modelo. ... . 45

D. Los modelos mentales o teorías implícitas .... . 45

E. Investigación empírica de modelos mentales/teorías implícitas (elicitación del conocimiento) . . .

3. Construcción autoorganizativa del conocimiento

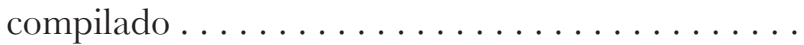

A. El conocimiento compilado y la "parte sabia" ericksoniana..................

B. Breve comentario sobre la "parte sabia" y el paradigma de la física cuántica ............

II. La mente como sistema generador de procesos estructurantes (caracterización teórica-conceptual precien-

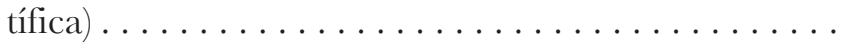

1. Poder explicativo del modelo en la interacción tera-

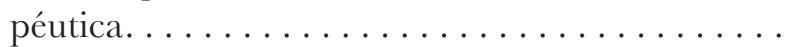

2. Poder explicativo del modelo en la construcción del conocimiento compilado . . . . . . . . . . . . . 60 
III. Versión contemporánea del concepto de "parte sabia": el inconsciente adaptativo . . . . . . . . . . . . 62

1. El inconsciente adaptativo en la investigación psicológica de frontera . . . . . . . . . . . . . . 62

2. El modelo del SGPES interpretado desde la descripción del inconsciente adaptativo . . . . . . . . . . 63

A. Propiedades sistémicas . . . . . . . . . . . . . . 64

B. Operación .................... 65

3. El inconsciente adaptativo sujeto a experimentación 65

4. El inconsciente adaptativo en diferentes contextos y el concepto de "parte sabia" . . . . . . . . . . . 67

5. Inconsciente adaptativo y constructivismo judicial . 70

CAPÍTULO TERCERO

METODOLOGÍA. TÉCNICAS ERICKSONIANAS $\Upsilon$ ELICITACIÓN DEL CONOCIMIENTO JUDICIAL EN LA INTELIGENCIA ARTIFICIAL APLICADA AL DERECHO . . . . . . . . . . . . . . . . . .

Técnicas ericksonianas: llaves para acceder al incons-

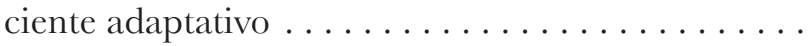

GapÍtulo GUARTO

RESUltados ......................... 79

I. Cambios posteriores a la inducción. . . . . . . . 79

II. Reservas sobre la verificación experimental de los resultados .................... 80

Conclusiones ....................... 81 


\section{ANEXO}

TAller Para la Elicitación Del GonOcimiento

JUDiGIAL $\ldots \ldots \ldots \ldots \ldots \ldots \ldots \ldots \ldots \ldots \ldots \ldots \ldots$

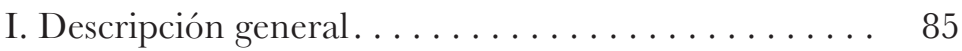

1. El juego de los nueve puntos. Creencias limitantes . 85

2. Orientando la percepción . . . . . . . . . . . 86

3. Nuestra habilidad para generar representaciones

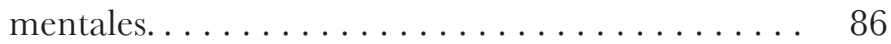

4. Ejercicio de meditación: contacto con el inconsciente y elicitación del conocimiento de los jueces expertos................... 87

II. Desarrollo del taller . . . . . . . . . . . . . . 88

1. Creencias limitantes. El ejercicio de los nueve puntos 88

2. Esquemas y percepción . . . . . . . . . . . . . . 89

3. Capacidad generativa de representaciones mentales. 92

4. Entrando en contacto con la respiración. . . . . . . 93

III. Inducciones . . . . . . . . . . . . . . . . . . . . 94

1. Primera inducción: encuentro conmigo como juez. 94

2. Segunda inducción: intervención para elicitación de conocimiento compilado................. 94

Bibliografía ..................... 97 
Este libro forma parte del acervo de la Biblioteca Juridica Virtual del Instituto de Investigaciones Juridicas de la UNAM

\section{CAPÍTULO PRIMERO}

\section{ANTEGEDENTES}

\section{INTRODUCGIÓN}

Sin duda alguna, vivimos en una época de cambios, de revisión de paradigmas, de surgimiento de nuevas interdisciplinas, de derrumbe de viejas concepciones...

En algún sentido puede decirse que estamos ante un nuevo renacimiento y digo "en algún sentido" porque hoy no hay moldes clásicos que revivir, sino un pensamiento nuevo por generar y de esa manera hacer surgir, de lo que existe, una nueva dimensión mejor que la que nos ha precedido y de la que actualmente prevalece.

Pero el cambio que se anuncia no parece ser simplemente un cambio más, o un cambio "uno", sino un cambio "dos" en términos de Watlzlawick; un cambio que puede llevarnos a un metanivel que permita ver en retrospectiva nuestro pensamiento y comportamientos actuales como enraizados en un sofisticado atavismo, en instintos primitivos de supervivencia y conflicto, un pensamiento que podría hacer emerger nuevos estados de armonía. Algo tan novedoso como lo conocido por las tradiciones budistas desde hace 2600 años.

Ello no significa, obviamente, el fin de la civilización actual y abogar por reiniciar de cero. Al contrario, la gran revolución que se vislumbra es particularmente integradora. Las reuniones del Dalai Lama con filósofos y científicos del más alto nivel, así como su participación en el lugar de honor en los congresos internacionales constructivistas, dan cuenta de ello. 
Este libro forma parte del acervo de la Biblioteca Juridica Virtual del Instituto de Investigaciones Juridicas de la UNAM

El presente trabajo aspira a ser una contribución modesta a dicho proceso integrador, mostrando de qué forma se pueden integrar las computadoras, el derecho, la epistemología constructivista, la filosofía y las técnicas ericksonianas, para hacer que algo aparentemente tan frío como una computadora pueda ayudar a realizar mejor algo tan humano como lo es la impartición de justicia.

Por lo que respecta al estatus de esta investigación como tesis de maestría para optar por el grado de maestro en psicoterapia ericksoniana, deseo resaltar mi convencimiento de que, de tiempo en tiempo, surgen en el firmamento académico luces capaces de ensanchar el universo del conocimiento hasta límites previamente insospechados.

Sin duda alguna, Milton Erickson ha sido una de esas luces, una estrella cuyo brillo se expande y deslumbra más y más en la medida en que se conoce mejor su obra.

No obstante de la grandeza intelectual de este hombre con alma de acero, capaz de superar todas las adversidades para incorporarse sobre sus frágiles piernas hasta convertirse en uno de aquellos gigantes en cuyos hombros podemos vislumbrar un horizonte interminable, su principal contribución a la humanidad es inmedible en términos del sufrimiento sanado a lo largo del mundo por parte de todos sus discípulos, de todas las nacionalidades. Quien esto escribe, no es sino uno más de quienes, de la mano de otro extraordinario ser humano, la doctora Teresa Robles, aspira a convertirse en un aprendiz más de estos magos del siglo XXI y, de su mano, contribuir a mejorar este mundo.

Como prevención conclusiva de esta introducción breve, debe resaltarse que lo que a continuación se expone no constituye una mera especulación de "ciencia ficción", pues forma parte de una investigación en proceso, financiada por el Consejo Nacional de Ciencia y Tecnología, Conacyt, que se realiza, básicamente, en el Instituto de Investigaciones Jurídicas de la Universidad Nacional Autónoma de México. 
Este libro forma parte del acervo de la Biblioteca Juridica Virtual del Instituto de Investigaciones Juridicas de la UNAM

\section{ERIGKSON Y EL DEREGHO}

A pesar de su formación en el terreno de la psiquiatría, en su vasta obra, Erickson destinó algunas de sus reflexiones al derecho.

Con la finalidad de contextualizar adecuadamente la presente investigación respecto al propio pensamiento ercksoniano acerca del derecho, a continuación se presenta un panorama breve de sus contribuciones en dicho terreno: ${ }^{1}$

1) En su artículo "The Inhumanity of Ordinary People", luego de hacer un recuento somero de algunas de las atrocidades más terribles que se han cometido en la historia moderna de la humanidad (la Santa Inquisición, el exterminio de los indios de Norte América, el Holocausto, etcétera), Erickson denuncia la falta de interés, por parte de la comunidad de psiquiatras y psicólogos de su época, por el estudio científico del comportamiento antisocial y destructivo, el cual no es exclusivo de aquellos a quienes se ha diagnosticado el padecimiento de alguna patología mental, sino que, en muchas ocasiones, es desplegado también por la gente "ordinaria" o "normal":

Throughout the ages everybody has tried to believe that normal psychological behavior includes only that which is good at the social level, and behavior adverse to the good of humanity has been attributed to various scapegoats. In recent times the murder of millions of people was attributed primarily to Hitler, and every "good" German defended his share in that effort at genocide as a proper carrying out of the orders of a superior. But we do not need to consider the offenses initiated by Hitler. We need only to look upon what happened to the aborigines of Tasmania, shot for food for the dogs of the settlers, to develop some unhappy but scientific thinking. One can recall in relatively recent history the nobility of the Puritans who came to New England and founded a colony so that they might establish the right of human beings

1 Agradezco la invaluable colaboración de mi asistente principal de investigación, el licenciado Edgar Aguilera García, para el desarrollo de esta sección. 
Este libro forma parte del acervo de la Biblioteca Juridica Virtual del Instituto de Investigaciones Juridicas de la UNAM

to worship the Deity in freedom and without restraint imposed by others. But what about their persecution of Roger Williams? How did it happen that such noble purposes led to the discovery that "the only good Indian is a dead Indian?... The world has been "kind" in overlooking the motivations of such examples as the treatment of Copernicus, the ravaging of the coast of Europe by the Vikings, or the sources of present day racial strife, preferring to discuss the behavior of humanity in terms of impersonal social forces. At times, man's inhumanity to man is given some euphemistic label, but no effort is made to investigate scientifically the extremes to which the normal, the good, the average, or the intellectual person or group will go if given the opportunity: consider the Spanish Inquisition, the Salem witch trials, or the introduction of slavery into a country dedicated to the right of everyone to equality and freedom. ${ }^{2}$

Erickson expresa la necesidad de investigar el comportamiento socialmente inaceptable en los siguientes términos:

The capacity for behavior unacceptable both to the individual and to society is an area that has long been overlooked, and this area requires careful scientific investigation far more than does acceptable behavior. Unacceptable behavior is and has been the basis of the serious social disorders rampant throughout history... It is time that society - particularly its psychologists and psychiatrists - takes a realistic view of the nature of undesirable and destructive human behavior and the extent to which, under stress or without stress, the individual, the group or an entire society can be led to enact it, so that understanding and perhaps eventually control of the ugly realities that have characterized human history since its beginning may result. ${ }^{3}$

2) En sus trabajos "Study of the Relationship Between Intelligence and Crime", "Criminality in a Group of Male Psychia-

2 Erickson, Milton, "The Inhumanity of Ordinary People", International Fournal of Psychology, octubre de 1968, pp. 277-279.

3 Idem. 
Este libro forma parte del acervo de la Biblioteca Juridica Virtual del Instituto de Investigaciones Juridicas de la UNAM

tric Patients", "Marriage and Propagation Among Criminals", "Some Aspects of Abandonment, Feeblemindedness, and Crime", Erickson muestra un gran interés por el estudio del comportamiento delictivo. Sin embargo, más que constituir investigaciones de carácter psiquiátrico o psicológico, su contribución se aproxima, más bien, al dominio de la sociología criminal.

Erickson pensaba que el enfoque tradicional para el abordaje del fenómeno criminal, que consideraba sólo aspectos económicos y sociales, debía complementarse con estudios de índole psiquiátrica y psicológica, sin que ello signifique que sus investigaciones en sí fueran psiquiátricas o psicológicas. Ilustra esta orientación el siguiente pasaje:

Formerly, only the dull prosaic facts of social and economic existence were considered the total sum of essential knowledge concerning the criminal. Quite otherwise now, a study of crime necessitates in addition an investigation into the behavior reactions, mental attitudes, intellectual and emotional endowments, physical development, habits, predilections, idiosyncrasies, and all possible intimate and personal details of the individual offender in his daily life. ${ }^{4}$

Entre los problemas que llamaron la atención de Erickson en este dominio, fueron constantes los siguientes:

- ¿Qué relación estadística existe entre el grado de inteligencia del individuo y la tendencia al comportamiento delictivo?

- ¿Qué relación estadística existe entre el haber tenido experiencias bélicas (participación en guerras) y la tendencia al comportamiento criminal?

- ¿Es el matrimonio efectivamente un factor de estabilidad que inhibe el comportamiento criminal?

4 Erickson, Milton, "Some Aspects of Abandonment, Feeblemindedness, and Crime", The American Fournal of Sociology, vol. XXXVI, núm. 5, marzo de 1931. 
Este libro forma parte del acervo de la Biblioteca Juridica Virtual del Instituto de Investigaciones Juridicas de la UNAM

- ¿Con qué frecuencia los criminales provienen de ambientes familiares disfuncionales?

- ¿Con qué frecuencia intervienen en la comisión de delitos quienes manifiestan alguna o varias de las psicopatologías reconocidas?

- ¿Cuál es la naturaleza de los delitos cometidos por las personas anteriores?

- ¿Con qué frecuencia los llamados "débiles mentales" (the feebleminded) cometen delitos tales como incumplimiento de obligaciones alimenticias, o abandono?

3) En su trabajo titulado "An Experimental Investigation of the Possible Antisocial Use of Hypnosis", Erickson se ocupa específicamente de la relación entre la hipnosis y el derecho, reflexionando acerca de las posibilidades de emplear la hipnosis para inducir la comisión de delitos.

Un pasaje singularmente representativo de su aportación en este terreno es el siguiente:

Instead of blind, submissive, automatic, unthinking obedience and acquiescence to the hypnotist and the acceptance of carefully given suggestions and commands, the subjects demonstrated a full capacity and ability for self-protection, ready and complete understanding with critical judgment, avoidance, evasion, or complete rejection of commands, resentment and objection to instrumentalization by the hypnotist, and for aggression and retaliation, direct and immediate, against the hypnotist for his objectionable suggestions and commands. In addition many demonstrated a full capacity to take over control of the hypnotic situation and actually did so by compelling the experimenter to make amends for his unacceptable suggestions. ${ }^{5}$

4) En su artículo "Negation or Reversal of Legal Testimony", y siempre vinculado con el derecho penal, Erickson analiza el

5 Véase Erickson, Milton, "An Experimental Investigation of the Possible Antisocial Use of Hypnosis", Psychiatry, núm. 2, agosto de 1939, pp. 391-414. 
Este libro forma parte del acervo de la Biblioteca Juridica Virtual del Instituto de Investigaciones Juridicas de la UNAM

fenómeno de la retracción de testigos que han sido víctimas de delitos sexuales, aun en casos en que los presuntos responsables hubieran resultado confesos ante el fiscal.

La siguiente cita ilustra el resultado de las investigaciones de nuestro autor en este ámbito del derecho procesal penal:

Such alteration of testimony is characterized by a complete change in the beliefs and understandings of the witness, effected by unrecognized factors within the personality. It occurs most frequently among the witnesses who are themselves the injured parties and, hence, have presumably every reason for telling only the truth, and it develops usually in relation to crimes of a personally horrifying, traumatic, or repugnant character. ${ }^{6}$

5) Una investigación más en el terreno del derecho procesal penal es efectuada por Erickson en su artículo "Concerning Present Inadequacies in the Legal Recognition and Handling of the Mentally Ill", en el cual se ocupa de hacer una apología de la psiquiatría como ciencia auxiliar del derecho en materia de periciales sobre la imputabilidad o inimputabilidad de los presuntos responsables de delitos.

La siguiente referencia da cuenta de ello:

The law properly provides that a person may be committed as mentally ill only on the basis of certain established facts. Lack of training and inexperience in psychiatry has resulted in innumerable instances of persons, actually psychotic and in need of institutional care, being committed illegally because the committing physicians' reports were not properly written, the necessary facts were not correctly established, and the court, in the rush of work and in the simple acceptance of mere opinion ordered such commitment. For example, the committing physicians' statements on one patient read, "This patient is insane, with catatonic dementia praecox, and should be sent to a mental hospital and treated for this condition.

6 Véase Erickson, Milton, "Negation or Reversal of Legal Testimony", Archives of Neurology and Psychiatry, vol. 40, septiembre de 1938, pp. 548-553. 
Este libro forma parte del acervo de la Biblioteca Juridica Virtual del Instituto de Investigaciones Juridicas de la UNAM

Such a statement is merely a personal opinion, is not substantiated by factual statements as required by law and hence the commitment based upon it was illegal. Furthermore, in this particular instance, although the patient was acutely psychotic and in need of immediate psychiatric care, the correct diagnosis was general paresis. Hence that patient could not possibly be legally committed as suffering from catatonic dementia praecox, and the commitment was an absolute denial of his legal rights and privileges. $^{7}$

De las referencias precedentes se obtienen las siguientes conclusiones:

- No obstante el interés de Erickson por temas jurídicos, su dominio se restringió básicamente al derecho penal, tanto sustantivo como procesal.

- Paradójicamente, ninguna de sus investigaciones en el terreno del derecho versa sobre la aplicación de las técnicas ericksonianas al dominio jurídico.

Una de las motivaciones centrales de este trabajo es rendir tributo a Milton Erickson, mostrando la utilidad de sus técnicas en la investigación jurídica contemporánea de frontera. De manera particular, en una de las más fascinantes interdisciplinas en proceso de consolidación a nivel internacional: la inteligencia artificial aplicada al derecho.

Por otra parte, debe resaltarse que, a pesar de su predominante trabajo teórico, la presente investigación no tiene un carácter meramente especulativo, pues las técnicas ericksonianas han sido efectivamente empleadas como parte de una investigación práctica, financiada por el Consejo Nacional de Ciencia y Tecnología, la cual aspira a constituir la primera implementación, a nivel internacional, de un sistema experto de ayuda a la

7 Erickson, Milton, "Concerning Present Inadequacies in the Legal Recognition and Handling of the Mentally Ill", Diseases of the Nervous System, vol. VII, núm. 4, abril de 1946. 
Este libro forma parte del acervo de la Biblioteca Juridica Virtual del Instituto de Investigaciones Juridicas de la UNAM

decisión judicial en ordenamientos jurídicos de familia romanogermánica.

Un factor de singular importancia es que la investigación en inteligencia artificial referida, de la cual, quien suscribe es responsable, queda comprendida dentro del marco de una investigación epistemológica más amplia, pues constituye uno de los dominios de reflexión de mi objeto de investigación principal desde hace ya varios años, con el cual aspiro a iniciar un nuevo paradigma en la comprensión del derecho: "el constructivismo jurídico".

A pesar de que dichos trabajos fueron iniciados mucho antes de entrar en contacto con el pensamiento ericksoniano, resulta especialmente gratificante encontrar que, tanto la teoría subyacente a la psicoterapia ericksoniana, como el constructivismo jurídico, suscriben los mismos presupuestos del constructivismo epistemológico, en proceso de elaboración en todo el mundo.

Por esta razón, y a efecto de comprender mejor los alcances del proyecto de referencia, se exponen a continuación, aunque sea sucintamente, las ideas principales de mi propuesta teórica.

\section{CONSTRUCTIVISMO ERICKSONIANO Y CONSTRUCTIVISMO JURÍDICO}

\section{La revolución constructivista en la historia de la epistemología}

El constructivismo emerge por todas partes como el tercer estadio en la evolución de la epistemología, después del derrumbe de las filosofias especulativa y empirista.

La primera, caracterizada por proporcionar explicaciones del mundo basadas en meras ideas, intuiciones y especulaciones sin confirmación empírica, se extendió de los orígenes de la filosofía misma al periodo comprendido entre finales del siglo XIX y principios del XX, cuando lo que hoy se suelen llamar "ciencias duras" se convirtieron en el paradigma del trabajo científico y monopolizaron la manera de obtener conocimiento mediante el método científico. 
Este libro forma parte del acervo de la Biblioteca Juridica Virtual del Instituto de Investigaciones Juridicas de la UNAM

A condición de admitir como plausible una mayor denotación para el término "paradigma" que la concedida originalmente por Kuhn, quien la reserva para las concepciones científicas dominantes en una época determinada, es posible decir que la epistemología subyacente al periodo especulativo constituye un primer paradigma que comprende subparadigmas menores en cortes sincrónicos diferentes.

Así, por ejemplo, a pesar de tener en común el carácter especulativo referido, es posible distinguir entre la teoría que sostiene que el conocimiento es posible a partir de la intuición que permite tener acceso a las esencias (Platón), de otra que afirma que el conocimiento es posible gracias a la revelación (periodo escolástico), o de otra según la cual se obtiene en virtud de la razón (periodo racionalista).

El derrumbe de la epistemología especulativa tuvo su génesis en el siglo XIX con los avances en lógica y matemáticas, y continuó con la física (teoría de la relatividad y mecánica cuántica) a principios del siglo XX. ${ }^{8}$

Con los nuevos avances los tres pilares en que se recargaba el conocimiento de dicho periodo cayeron por tierra: contra la idea de la definitividad de la lógica aristotélica surgió la lógica matemática cristalizada en los trabajos de Frege y Russell; la concepción del espacio como una síntesis a priori, característica de la geometría euclidiana, fue derrumbada por las geometrías no euclidianas de Bolyai y Lobatchewski y, finalmente, las nociones de un espacio y un tiempo absolutos, sustentadas en la física newtoniana, fueron vencidas por la teoría de la relatividad de Albert Einstein.

El efecto de esta revolución científica en el ámbito de la epistemología fue el colapso de la fundamentación filosófica de la vieja ciencia: las categorías del conocimiento de la teoría del conocimiento kantiana resultaron inadecuadas para dar cuenta de la "nueva realidad". Si bien es cierto que Kant puede considerarse el más importante precursor del constructivismo epistemológico

8 García, Rolando (coord.), Piaget y el problema del conocimiento, la epistemología genética y la ciencia contemporánea, Madrid, Gedisa, 1997, p. 16. 
Este libro forma parte del acervo de la Biblioteca Juridica Virtual del Instituto de Investigaciones Juridicas de la UNAM

por resaltar el papel activo del sujeto cognoscente en la construcción del conocimiento, también lo es que su teoría acerca de cómo se logra el conocimiento científico quedó sin sustento. ${ }^{9}$

El colapso producido por la nueva situación llevó a la búsqueda de una nueva fundamentación filosófica del quehacer científico y convocó a las más brillantes inteligencias de su época, quienes se esforzaron, individual o colectivamente (círculos de Viena y Berlín), en construir una nueva epistemología. ${ }^{10}$ Los esfuerzos rindieron su fruto y surgió el empirismo científico, cuyo credo común fue considerar que "la observación sensorial es la fuente primera y el juez último de todo conocimiento". ${ }^{11}$

En concordancia con este postulado fundamental, se suscribió una teoría del significado, según la cuál sólo vale la pena ocuparse de enunciados descriptivos, susceptibles de ser evaluados en términos de verdadero o falso; se privilegió una teoría de la verdad por correspondencia; se emprendió una lucha feroz contra todo pensamiento metafísico; se asumió que la realidad era externa y completamente independiente del sujeto cognoscente y que su conocimiento objetivo estaba asegurado por medio del empleo del método científico.

Sin embargo, a pesar de sus múltiples e innegables avances, actualmente, y sobre todo como producto de los avances de las ciencias cognitivas, el núcleo central de la epistemología empirista ha dejado de tener vigencia, debido a que se ha demostrado que su creencia en una realidad externa independiente del sujeto cognoscente, así como su confianza en la constatación neutral de los sentidos, es absolutamente ingenua y es así que surge lo que se ha dado en llamar la "nueva filosofía de la ciencia", entre cuyos representantes se encuentran Kuhn, Lakatos, Feyerabend, Hanson, etcétera. ${ }^{12}$

$9 \quad$ Ibidem, pp. 17-19.

10 Ibidem, p. 20.

11 Ibidem, p. 22.

12 Para una visión sucinta de la "Nueva Filosofía de la Ciencia", véase: http://wrwre.bun.kyoto-u.ac.jp/ suchii/philsci_j7.html. 
Este libro forma parte del acervo de la Biblioteca Juridica Virtual del Instituto de Investigaciones Juridicas de la UNAM

Si el postulado central del empirismo consistía en sostener la existencia de una realidad objetiva, independiente de todo sujeto cognoscente, lo que caracteriza a la nueva epistemología constructivista es la tesis, según la cual no existe una realidad objetiva, independiente de las teorías o esquemas cognitivos del pensamiento común, los cuales no son sino constructos elaborados por los sujetos cognoscentes (científicos, filósofos, hombre común, etcétera).

De esta manera, si para el empirismo el papel del sujeto cognoscente se limitaba a reflejar la realidad externa como si fuera un espejo, para el constructivismo, dicho sujeto tiene un papel activo fundamental, pues lo considera como un procesador de información cuyos "productos" constituyen representaciones mentales que proyecta al exterior en forma de realidad.

Parafraseando a Einstein en su alusión a las teorías científicas, puede decirse que no es cierto que la realidad determine nuestras teorías, sino que son nuestras teorías las que determinan lo que podemos percibir como realidad. Así, tal como dice Bunge, un hueso fósil resulta relevante para una teoría de la filogénesis no por el hueso en sí, sino en función de la teoría.

Con respecto al fundamento del nuevo paradigma, debe destacarse la importancia de las ciencias cognitivas, muy particularmente, de la psicología cognitiva, la cual, se consolida gracias a cuatro hechos fundamentales ocurridos durante la segunda mitad del siglo XX:

1) El surgimiento y los logros alcanzados a finales de los cincuenta y principios de los sesenta dentro de las áreas de la tecnología cibernética.

2) El establecimiento de la lingüística como especialidad antropológica.

3) El amplio desarrollo que tuvo la teoría de la información en psicología. 
Este libro forma parte del acervo de la Biblioteca Juridica Virtual del Instituto de Investigaciones Juridicas de la UNAM

4) La aparición del nuevo neoasociacionismo, que hace una fusión o integración de los tres puntos anteriores, dentro del terreno de la psicología. ${ }^{13}$

\section{Caracterización General de la Epistemología Constructivista} en el ámbito de la Ciencia

Los postulados centrales del constructivismo frente al empirismo son los siguientes:

1) La realidad es un constructo.

2) Los enunciados observacionales son constitutivos de sus "observables".

3) En algún sentido, los enunciados observacionales son constitutivos de la realidad.

4) La verdad de los enunciados observacionales no opera por medio de simple correspondencia.

5) Las teorías científicas no se construyen a partir de los datos brutos, sino de esquemas cognitivos previos, originados a partir de otras teorías y problemas de interés del científico.

6) No es posible reducir los términos teóricos a enunciados observacionales, debido a su cobertura explicativa.

7) Respecto de un mismo dominio es posible la coexistencia de teorías rivales.

8) La decibilidad entre teorías rivales no obedece únicamente a factores racionales, sino también, a otros de tipo contextual.

9) Un observable es considerado una evidencia relevante a partir de lo que la teoría considera como evidencia relevante.

10) Una objeción teórica no es siempre concluyente, pues existe la posibilidad de introducir hipótesis ad hoc. El criterio para determinar el carácter concluyente o no de una objeción, en buena medida, es determinado por la propia teoría.

13 Ibidem, p. 29. 
Este libro forma parte del acervo de la Biblioteca Juridica Virtual del Instituto de Investigaciones Juridicas de la UNAM

\section{Epistemología constructivista y realidad cotidiana}

¿Qué significa asumir que la realidad es un constructo? Una forma de explicarlo es a través de lo que podríamos llamar el mundo empírico más elemental, el de las cosas, integrado por mesas, por sillas, por piedras i. e., lo que supuestamente está al alcance de todos nosotros y que, por tanto, es constitutivo de lo que llamaríamos "la realidad común".

Los avances de las ciencias cognitivas contemporáneas nos permiten relativizar, de manera importante, la idea de la existencia de un mundo objetivo y estructurado independientemente del sujeto cognoscente. Me voy a permitir citar algunos trabajos en el ámbito de las ciencias cognitivas:

...hasta donde sabemos, nuestros receptores son transformadores, transforman un tipo de energía en otro, es decir, transforman un tipo de energía, como podrían ser las ondas electromagnéticas de la visión, ondas de presión como el sonido, cambio mecánicos de nuestra piel como el tacto, partículas químicas como el gusto y el olfato, en eventos eléctricos para que tal mensaje sea entendido en nuestro cerebro. Está claro, deducido de esto último, que el entramado íntimo de nuestro cerebro, no entiende nada de las energías que existen en el mundo real a menos que sean traducidas. $\mathrm{Y}$ es que nuestro cerebro sólo usa y entiende de señales eléctricas para procesar la información que recibe del medio ambiente que le rodea. Lo realmente sorprendente es que hasta donde la neurociencia nos va desentrañado, la realidad que construye nuestro cerebro no es una traducción fiel de la realidad que existe fuera de nosotros. La realidad externa, la que vemos todos los días, de animales, cosas, etcétera, es un constructo que hace nuestro cerebro sobre la base de su funcionamiento que, en alguna medida, viene preprogramado por los logros obtenidos por la evolución. ${ }^{14}$

Otra cita del ámbito experimental es la siguiente:

14 Mora, Francisco, ¿Cómo funciona el cerebro?, Madrid, Alianza, 2000, pp. 26 y 27. 
Este libro forma parte del acervo de la Biblioteca Juridica Virtual del Instituto de Investigaciones Juridicas de la UNAM

Unos niños que nacen con cataratas, se operan hasta los 12, 14 años, su aparato funciona perfectamente, lo cual nos haría suponer que este hecho permitiría que ellos podrían percibir y reflejar la realidad tal cual. Durante los primeros días, a pesar de la normalidad de sus ojos, este mundo visible carecía para ellos de significado y sólo podían reconocer objetos familiares como un bastón o su silla favorita mediante exploración manual. Después fue necesario un lento proceso de aprendizaje para que aprendieran a percibir el significado de las luces y de las sombras. Después de un gran periodo de enseñanza, la capacidad de reconocimiento visual mejoró sin alcanzar nunca una normalidad completa, por ejemplo, la distinción entre un cuadrado y un hexágono requiere siempre de un laborioso y con frecuencia erróneo recuento manual de las esquinas y en ocasiones confundían un caballo con un gallo debido a que ambos tenían cola. ${ }^{15}$

Esto nos hace ver que, incluso, el nivel más elemental de la realidad es producto de una construcción cognitiva.

\section{Constructivismo ericksoniano}

Sin duda, una de las características más impresionantes del pensamiento ericksoniano radica en ser pionero de la revolución epistemológica constructivista en cuya consolidación nos encontramos inmersos a nivel mundial.

A ello hace referencia la doctora Teresa Robles en la parte correspondiente a la Introducción a la psicoterapia ericksoniana, incluida dentro del cuaderno de trabajo del primer semestre de la maestría, en los siguientes términos:

Su epistemología es constructivista: no podemos conocer la realidad tal cual es. Estamos limitados por nuestros sentidos; pero la realidad que construimos en nuestro mundo interno, en la imaginación, se proyecta en el mundo externo, porque a partir de ese momento actuamos, vivimos y sentimos en función de esa rea-

15 Ibidem, p. 30. 
Este libro forma parte del acervo de la Biblioteca Juridica Virtual del Instituto de Investigaciones Juridicas de la UNAM

lidad interna. Se trata entonces de construir realidades internas que después se den automáticamente en el afuera. ${ }^{16}$

En su obra La psicoterapia, un proceso de autoconstrucción, Yolanda Aguirre caracteriza al constructivismo en los siguientes términos:

El constructivismo es radical porque rompe con las convenciones y desarrolla una teoría del conocimiento en la cual éste ya no se refiere a una realidad ontológica "objetiva", sino que se refiere exclusivamente al ordenamiento y organización de un mundo construido de nuestras experiencias. El constructivista radical se encuentra enteramente de acuerdo con Piaget, quien dice: "la inteligencia organiza al mundo organizándose a sí misma." ${ }^{17}$

Para ella, los principios básicos del constructivismo son los siguientes:

1) El conocimiento no se recibe pasivamente, ni a través de los sentidos, ni por medio de la comunicación, sino que es construido activamente por el sujeto congnoscente.

2) La función de la cognición es adaptativa y sirve a la organización del mundo experiencial del sujeto, no al "descubrimiento" de una realidad ontológica objetiva. ${ }^{18}$

La ubicación del constructivismo dentro del panorama de la filosofía corresponde al pragmatismo:

El constructivismo de alguna manera se relaciona con el pragmatismo, porque comparte la idea de que las elecciones que hacemos están en correspondencia con la utilidad. La ciencia moderna no nos permite manejarnos porque exista una correspondencia con

16 Robles, Teresa, Terapia cortada a la medida, México, Instituto Milton H. Erickson de la Ciudad de México, 1994.

17 Aguirre, Yolanda, La psicoterapia, un proceso en construcción, México, Alom Editores, 2004, p. 48.

18 Idem. 
Este libro forma parte del acervo de la Biblioteca Juridica Virtual del Instituto de Investigaciones Juridicas de la UNAM

la verdad, sino sólo porque permite manejarnos... Los constructivistas pueden sostener la compatibilidad con los modelos científicos que nos permiten "manejarnos" bien en áreas específicas de la experiencia. Por ejemplo, puedo mencionar, acerca de la neurofisiología del cerebro, que ante un análisis fisiológico sólo encontramos un disparo electroquímico de las neuronas individuales, pero no existe ninguna "realidad" en los términos que lo suponemos allá afuera. ${ }^{19}$

Como se verá adelante, estos supuestos presentados en el terreno de la psicoterapia son completamente compatibles con los subyacentes al constructivismo jurídico que estoy interesado en desarrollar.

\section{Constructivismo jurídico}

\section{A. El constructivismo jurídico en el contexto de la historia de la filosofía del derecho}

Los grandes esquemas epistemológicos referidos anteriormente $i$. e., los correspondientes a las filosofias especulativa y empirista, dejaron sentir su impacto en la construcción de concepciones generales del derecho.

En algún sentido, puede sostenerse que dichas concepciones no han sido sino productos que surgen de la mente de los teóricos de distintas épocas, como productos de la epistemología disponible en cada momento. Así, no es de extrañar que durante el periodo especulativo, y siguiendo la tradición escolástica, haya surgido la teoría iusnaturalista con base teológica representada, básicamente, por Tomás de Aquino en su Suma Teológica.

De igual manera, es posible observar el surgimiento de concepciones del derecho construidas desde los supuestos del empirismo, durante el periodo de mayor influencia del mismo. Por

19 Idem. 
Este libro forma parte del acervo de la Biblioteca Juridica Virtual del Instituto de Investigaciones Juridicas de la UNAM

ejemplo, la jurisprudencia sociológica,${ }^{20}$ el realismo escandinavo, el realismo americano ${ }^{21} \mathrm{y}$, en una versión un tanto distinta del positivismo, la teoría normativista contemporánea, cuyo punto de partida es posible encontrar en los trabajos de Austin ${ }^{22}$ y Kelsen. ${ }^{23}$

Desde luego, mostrar que las concepciones jurídicas son productos que emergen a partir de los supuestos epistemológicos disponibles por sus creadores, no implica sostener que al surgir unas, desaparezcan las anteriores, pues, como es obvio, pueden coexistir compitiendo entre sí.

Dentro de este panorama histórico-epistemológico podemos ubicarnos a nosotros mismos, juristas y operadores jurídicos de nuestro tiempo, como productos de la socialización profesional ocurrida en nuestras facultades de derecho, a partir del paradigma normativista positivista: para nosotros, el derecho es cuestión de normas, de igual manera que para un jurista de la época racionalista, en que estaba en vigor la jurisprudencia de conceptos, ${ }^{24}$ el derecho era una arquitectura conceptual abstracta, de la que, supuestamente, se podría inferir la solución a cualquier problema jurídico por medio de deducción, o del modo en que, para otros, el derecho era una cuestión de prescripción divina.

Sin embargo, en congruencia con lo señalado, una vez que el supuesto epistemológico desde el que se ha construido el normativismo, entra en crisis, la propia concepción del derecho en él fundamentada, tiene que ser revisada, punto en el cual hace su aparición el constructivismo jurídico.

20 Entre cuyos máximos representantes se encuentra el jurista norteamericano Roscoe Pound. Véase Pound, Roscoe, An Introduction to the Philosophy of Law, Estados Unidos, Yale University Press, 1959, p. 212.

21 Véase http://en.wikipedia.org/wiki/Legal_realism y http://wrwrequestia.com/ PM. qst: $a=0 \mathcal{E}^{2} d=5009817364 \mathcal{E}^{2} e r=$ deny.

22 Austin, John, The Province of Jurisprudence Determined, Estados Unidos, Prometheus Books, 2000.

23 Kelsen, Hans, The Pure Theory of Law, Estados Unidos, Lawbook Exchange, 2005.

24 Cuyo máximo representante fue Rudolf Von Jhering. De él, véase Von Jhering, Rudolf, Law as a Means to an End, Londres, Macmillan, 1998. 
Este libro forma parte del acervo de la Biblioteca Juridica Virtual del Instituto de Investigaciones Juridicas de la UNAM

$\mathrm{Al}$ respecto de la confrontación entre normativismo y constructivismo jurídico, en otro trabajo, he dicho lo siguiente:

Las restricciones metodológicas impuestas por el normativismo positivista, paradigma en el que somos socializados los juristas, impiden que podamos percibir, identificar, explicar, comprender y manipular los procesos mediante los cuales el derecho incide en la realidad social.

La realidad social no es necesaria, sino contingente: es un "constructo", resultante de los fenómenos psicosociales que están en la base de las interacciones que tienen lugar entre los miembros de toda sociedad.

En la construcción social de la realidad participan múltiples variables, una de las cuales es el derecho.

El derecho incide en la construcción social de la realidad cuando completa un ciclo que inicia con la existencia del texto jurídico positivo, continúa con el procesamiento de este insumo cognitivo por parte del sujeto cognoscente, da lugar a determinados estados psicológicos (que incluyen estados mentales) y culmina con la conducta social llevada a cabo sobre la base de los estados referidos, en los términos prescritos por la norma. Esta conducta social es la conducta jurídica.

De lo anterior se sigue que la norma jurídica, entendida como proposición lingüística, es simplemente un inicio, una condición necesaria, pero no suficiente para que la conducta jurídica tenga lugar.

Puede acontecer que las normas jurídicas no tengan impacto en los procesos de construcción social de la realidad debido a que en el trayecto que va de la norma a la acción no ocurran determinados fenómenos psicosociales (por ejemplo, el conocimiento del derecho). Esto puede ser el resultado de la no satisfacción de condiciones necesarias para la verificación de dichos fenómenos (verbigracia, que no haya forma de conocer textos legales).

También puede ocurrir que en el trayecto referido surjan fenómenos adicionales a los requeridos para que opere la eficacia normativa, así como que incidan en la construcción de una realidad social contraria a la prescrita (por ejemplo, que el derecho se 
Este libro forma parte del acervo de la Biblioteca Juridica Virtual del Instituto de Investigaciones Juridicas de la UNAM

conozca y no obstante, se incumpla porque la interacción social eficaz en un trámite administrativo requiera del soborno).

En ciertos casos, la conducta contraria al derecho se construye mediante un ejercicio deliberado en el que se "manipulan" las normas jurídicas para producir la conducta ilícita; es decir, paradójicamente, la norma jurídica es condición de la conducta contraria a la que prescribe (un caso: para que la corrupción administrativa tenga lugar debe ser realizada por un funcionario con determinadas facultades definidas en la ley).

De todo lo anterior se concluye que, para comprender el papel del derecho en la construcción social de la realidad, es necesario complementar el enfoque normativista con un enfoque cognitivo-conductual i.e., realizar una investigación insterdisciplinaria. La metodología resultante de dicha interacción constituiría la base de un paradigma alternativo que proponemos denominar "constructivismo jurídico". ${ }^{25}$

\section{B. Marco conceptual básico del constructivismo jurídico}

\section{a. Constructivismo epistemológico como Weltanschaunng}

En el proceso actual, aún no podemos hablar de constructivismo, sino de constructivismos. Por ejemplo, de constructivismo radical, social, epistemológico, pedagógico, (y dentro del pedagógico, podemos hablar del genético, ausbeliano, etcétera).

25 Véase Cáceres, Enrique, "Psicología y constructivismo jurídico: apuntes para una transición paradigmática interdisciplinaria”, en Muñoz de Alba Medrano, Marcia (coord.), Violencia social, México, UNAM, Instituto de Investigaciones Jurídicas, 2002, pp. 7-9. La cita de referencia ha sido transcrita prácticamente en forma literal a como aparece en el artículo de referencia, con una pequeña modificación resultante de nuevas reflexiones por parte del autor, misma que ha sido resaltada mediante el uso de versales y negritas. En el original se habla de "enfoque psicologista" en lugar de "enfoque cognitivoconductual". 
Este libro forma parte del acervo de la Biblioteca Juridica Virtual del Instituto de Investigaciones Juridicas de la UNAM

Una clasificación más próxima al derecho es proporcionada por el doctor Vittorio Villa, quien refiere: el constructivismo éticopolítico, social, sistémico, empirista, sociológico y pospositivista.

Esto significa que no tenemos aún un concepto unívoco de constructivismo y que las aportaciones que puedan realizarse respecto a la elaboración del concepto de constructivismo jurídico pueden también contribuir a la construcción del concepto general.

Sin embargo, a pesar de que las referidas versiones de constructivismo son elaboradas en marcos teóricos muy diferentes, abordando problemas muy distintos, pueden considerarse propiedades comunes en el uso de las expresión "constructivismo": 1) que el sujeto cognoscente construye la realidad; 2) que el sujeto cognoscente es, por tanto, un procesador de información; 3) que lo que percibimos como real es una proyección de las representaciones mentales del sujeto cognoscente, mediante las que estructura la información percibida en el "mundo exterior", de modo semejante a lo que sostiene la gestalt.

En este sentido, puede sostenerse que, aun en esta etapa, el constructivismo, lejos de poder considerarse una teoría, puede caracterizarse como el germen de una metadisciplina, un nuevo Weltanschaunng, ${ }^{26}$ o manera de organizar nuestra comprensión (comprensión-construcción) del mundo. Es decir, que su estatus se asemeja al de la teoría general de sistemas, cuya aplicación no se limita a un área o áreas científicas particulares, y pue-

26 Checkland se refiere a Weltanschauung en los siguientes términos: "ya sea que nos demos cuenta o no de ello, nosotros observamos a los datos en bruto vía un marco mental, o visión del mundo. Si nosotros observamos una votación, vemos a la gente votar; no vemos «equis que se hace en hojas de papel» sino «seres humanos tomando parte en el proceso democrático». Nosotros atribuimos un significado a la actividad observada cuando relacionamos a ésta con una imagen más grande que nuestra mente proporciona. La actividad observada sólo tiene significado para nosotros, de hecho, en términos de una imagen particular del mundo o Weltanschauung, que en general damos por hecha". Cfr., Checkland, Peter, Pensamiento de sistemas, práctica de sistemas, México, Noriega Editores, 1993, p.244. 
Este libro forma parte del acervo de la Biblioteca Juridica Virtual del Instituto de Investigaciones Juridicas de la UNAM

de adaptarse, tanto al dominio de la formalización matemática, como a los sistemas económicos, sociales e incluso, a las llamadas ciencias de la administración.

El carácter metadisciplinario que está adquiriendo el constructivismo se pone de manifiesto, de forma clara, cuando se le contrasta con los esquemas epistemológicos precedentes, pues aquél no pretende rivalizar con éstos y presentarse como "La epistemología" i. e., la epistemología correcta. Para el constructivismo, tanto la especulación metafísica, como la explicación empirista, no son otra cosa sino formas distintas de procesar insumos diferentes para generar esquemas explicativos distintos, cada uno de mayor o menor utilidad, en función de la época en cuestión y los problemas a abordar.

Por otra parte, debe destacarse que, a excepción del constructivismo radical, ${ }^{27}$ ser constructivista no significa defender un subjetivismo absurdo, ni un solipsismo y mucho menos, sostener que todo cuanto acontece es producto de nuestra imaginación, despreciando así, la dimensión empírica y los innegables avances del método científico. La diferencia estriba en que para el constructivista la dimensión empírica también es un constructo plausible desde los marcos de ciertos esquemas mentales.

\section{b. Conceptos básicos del "constructivismo jurídico"}

De la misma manera que ocurre con la teoría general de sistemas, es posible distinguir entre problemas metodológicos propios de la metadisciplina y los problemas metodológicos de una disciplina particular en la que se está buscando aplicar la teoría general.

A continuación, me ocuparé de esbozar algunos conceptos básicos de la concepción del constructivismo jurídico que propongo:

27 Defendido por ejemplo por Von Foerster. Véase Segal, Lynn, The Dream of Reality, 2a. ed., Springer, 2006. 
Este libro forma parte del acervo de la Biblioteca Juridica Virtual del Instituto de Investigaciones Juridicas de la UNAM

i) Estipulación de "derecho" para el constructivismo jurídico

Como he dicho en otro trabajo, ${ }^{28}$ el término "derecho" es polisémico, no únicamente en cuanto a los usos comunes del lenguaje, sino también, en sus acepciones teóricas. De esta manera, podemos distinguir entre un significado iusnaturalista de la expresión, de otro normativista, de otro realista, de otro analítico, etcétera.

Como también he indicado, lejos de pretender identificar cuál es la "verdadera" definición teórica de la expresión, lo cual lleva a un callejón sin salida, resulta conveniente tomar en cuenta que la justificación de cada uno de esos significados debe buscarse al interior de la teoría que lo propone en función de sus finalidades explicativas.

Lo que deseo señalar con esto, es que, bajo ningún sentido, debe entenderse que pretendo proporcionar "la" definición "verdadera" de "derecho", que busque desplazar a las demás. Simplemente, haciendo uso de mi derecho a la estipulación lingüística y, justificándola dentro del marco teórico del constructivismo jurídico, propongo la siguiente definición.

Para el constructivismo jurídico, el término "derecho" denota un sistema complejo constituido por:

A) El conjunto de insumos jurídico cognitivos (leyes, decretos, tesis jurisprudenciales, teorías dogmáticas, teorías generales del derecho, etcétera).

B) Las reglas de procesamiento de los insumos referidos en el inciso A) por parte de los juristas ${ }^{29}$ (reglas de interpreta-

28 Cáceres, Enrique, ¿Qué es el derecho? Iniciación a una concepción lingüística, 2a. ed., México, Cámara de Diputados, LVIII Legislatura-UNAM, 2001, p. 71.

29 Para efectos de economía expositiva doy al término jurista un sentido amplio que comprende no únicamente a los teóricos del derecho, tanto particulares como generales, sino también a los operadores jurídicos prácticos tales como los jueces, los abogados, etcétera. 
Este libro forma parte del acervo de la Biblioteca Juridica Virtual del Instituto de Investigaciones Juridicas de la UNAM

ción, metodología para realizar reconstrucciones normativas, etcétera).

C) Los productos cognitivos de los juristas, resultantes del procesamiento referido en el inciso B) (arborescencias semánticas, mapas mentales, reconstrucciones normativas, imágenes mentales de hechos y actos jurídicos, etcétera).

D) Las conductas realizadas por los juristas a partir de los productos cognitivos referidos en el inciso $\mathrm{C}$ ), incluyendo a las comunicativas.

E) Los insumos jurídicos, reglas de procesamiento de información, representaciones sociales y conductas efectuadas por la sociedad civil, a partir de dichas representaciones.

F) La incidencia de las conductas de los juristas y sociedad civil en los procesos de construcción social de la realidad.

Como es fácil percibir, una diferencia fundamental entre el normativismo y el constructivismo jurídico estriba en que aquél construye sus explicaciones sin considerar la forma en que el derecho incide en la realidad social, sino centrándose de manera "pura y aséptica", en el concepto de norma jurídica, mientras que el constructivismo busca poner al derecho nuevamente en contacto con la vida social, pero, sin ignorar los logros del normativismo como criterio básico de la identificación del derecho.

Dicho en otros términos, el constructivismo jurídico no ignora la dimensión normativa del derecho, sino que la presupone al considerar que las normas jurídicas son los insumos más relevantes en el procesamiento de información por parte de los sujetos cognoscentes u operadores jurídicos, pero no los únicos. Junto con ellos son procesados otros insumos, sin los cuales no es posible realizar las representaciones mentales desde las que se puede participar en los contextos comunicativos jurídicos. ${ }^{30} \mathrm{Tal}$ es el caso del discurso de las teorías dogmáticas, el discurso jurisprudencial, el discurso de la teoría general del derecho, etcétera.

30 Cáceres, Enrique, "Pasos hacia una teoría jurídica comunicativa", Crítica Furídica, México, núm. 16, 1995. 
Este libro forma parte del acervo de la Biblioteca Juridica Virtual del Instituto de Investigaciones Juridicas de la UNAM

En este sentido, cabe señalar otra diferencia entre el constructivismo y la presuposición de las normas como condiciones de identificación de conductas jurídicas entre la diversidad de conductas sociales no jurídicas. Así, mientras que para Kelsen una norma jurídica es suficiente para identificar una conducta jurídica en el mundo, la versión de constructivismo que propongo asume que los juristas no operan sólo con los enunciados normativos, sino a partir de los productos obtenidos del procesamiento de esos insumos conjuntamente con los de la dogmática, la teoría general del derecho, todos los cuales son extranormativos. A mi juicio es esta concepción constructivista, y no la kelseniana, la que permite percatarse de que, para participar en un litigio penal, no es suficiente saber leer y tener a la mano el código penal, sino realizar una sistematización cognoscitiva que integre las características del caso particular con el código penal, conjuntamente con alguna teoría general del delito.

ii) Definición de "constructivismo jurídico"

Una vez propuesta una estipulación para "derecho", proponer una estipulación de "constructivismo jurídico" resulta fácil:

Constructivismo jurídico denota al enfoque epistemológico y metodológico cuyo objetivo es explicar al conjunto de fenómenos denotados por "derecho" en la manera en que ha sido estipulado en el apartado a.

iii) Dominios del constructivismo jurídico

A partir del supuesto epistemológico que considera a los sujetos cognoscentes como procesadores de información y productores de su realidad, es posible distinguir diferentes dominios de reflexión del constructivismo jurídico, interconectados ineludiblemente, pero diferenciables por el tipo de problemas que los caracterizan. Dichos dominios son: 
Este libro forma parte del acervo de la Biblioteca Juridica Virtual del Instituto de Investigaciones Juridicas de la UNAM

A) Constructivismo jurídico metajurisprudencial: su objeto consiste en reflexionar sobre el estatus de las teorías conceptuales del derecho. Entre sus problemas se encuentran: ¿qué diferencias y semejanzas existen entre las teorías conceptuales del derecho y las teorías científicas?, si las teorías jurídicas no son contrastables directamente con un referente empírico con el cual confrontarla, entonces, ¿cómo es posible determinar que una teoría jurídica es correcta?, ¿con qué criterios decidir que una teoría es mejor que otra?, etcétera.

B) Constructivismo jurídico cognoscitivo: se encarga de estudiar los insumos jurídicos, formas de procesamiento y estados emergentes o supervenientes que tienen lugar en la mente de los operadores jurídicos (abogados, jueces, notarios, etcétera) como paso previo a su participación en los contextos comunicativos jurídicos y, por tanto, incidir, a través del lenguaje, en los procesos de construcción social de la realidad.

C) Constructivismo jurídico vinculado con los problemas de representación del conocimiento jurídico en el ámbito de la inteligencia artificial aplicada al derecho.

D) Constructivismo jurídico pedagógico: se encarga de hacer propuestas alternativas a las formas tradicionales de enseñanza del derecho, bajo el supuesto de que, como dijera en una plática informal mi buen amigo el profesor Burkhard Schaffer: "el derecho no es sino lo que enseñamos y como lo enseñamos en nuestras facultades de derecho".

E) Constructivismo jurídico sociorepresentacional: está encargado de estudiar la forma en que las normas jurídicas inciden en los procesos de construcción social de la realidad por parte de la sociedad civil.

F) Constructivismo jurídico institucional: se enfoca al estudio del papel de las instituciones jurídicas como generadores masivos de estados de cosas configurantes de la realidad social. 
Este libro forma parte del acervo de la Biblioteca Juridica Virtual del Instituto de Investigaciones Juridicas de la UNAM

Los dominios del constructivismo jurídico se encuentran íntimamente vinculados de la siguiente manera:

A) Se parte de una teoría que considera a la mente como un procesador de información de corte conexionista y autoorganizativo, desde el que se puede explicar la manera en que los sujetos cognoscentes construyen la realidad (constructivismo epistemológico).

B) Se asume que la mente de los científicos, al generar sus modelos, tanto formales como conceptuales, como la de los operadores jurídicos, es también un procesador de información, sólo que opera con insumos y reglas de procesamiento características de su gremio (método científico), y cuyos productos teóricos son constitutivos de modelos de realidad científica en los que se puede interactuar enactivamente, si la teoría es correcta, lo cual, no quiere decir "verdadera" en el sentido absoluto del empirismo ingenuo (constructivismo científico).

C) La misma teoría de la mente es supuesta respecto de quienes, como los filósofos políticos, éticos, o filósofos del derecho, se encargan de elaborar teorías conceptuales no susceptibles de verificación directa sobre observables por ellas constituidas, pero que tienen importantes consecuencias en la configuración de las representaciones mentales y sociales desde las que se construye el mundo del derecho (constructivismo jurídico metajurisprudencial).

D) El constructivismo jurídico cognoscitivo: considera la mente de los operadores jurídicos de igual manera, con la diferencia de que asume que operan con insumos diferentes a los teóricos del derecho, con reglas de procesamiento de información propias de su actividad técnica, mediante la cual, participan directamente en la configuración social de la realidad, como cuando, por ejemplo, dictan una sentencia.

E) La relación entre constructivismo cognoscitivo e inteligencia artificial aplicada al derecho resulta evidente ya que, 
Este libro forma parte del acervo de la Biblioteca Juridica Virtual del Instituto de Investigaciones Juridicas de la UNAM

los problemas de representación del conocimiento jurídico, característicos de esta disciplina, implican dar cuenta de parte de los procesos de información de los operadores expertos, pues, no toda la complejidad de los mismos puede ser modelada en computadora.

F) El constructivismo jurídico institucional recoge parcialmente el estudio del constructivismo cognoscitivo para dar cuenta de la manera en que la estructura organizativa de una institución puede incidir, de manera controlada y dirigida, en su funcionamiento como agente socializador y participar en procesos de construcción social de la realidad.

G) El constructivismo pedagógico tiene un impacto sumamente importante en la reconfiguración de nuestra manera de producir insumos de enseñanza e impartir la enseñanza misma, a partir de la teoría de la mente referida e incidir, tanto en la dimensión universitaria, como en el diseño de cursos de inducción en instituciones jurídicas.

H) El constructivismo jurídico sociorepresentacional, el cual da cuenta de la forma en que el derecho incide en la generación de las representaciones sociales que están en la base de las interacciones y prácticas sociales de índole jurídica, resultantes de la función socializadora de las instituciones públicas y operadores jurídicos, y de la manera en que, mediante la conducta social resultante, revierten en la propia matriz de socialización, cerrándose, de esta manera, un círculo perfecto.

\section{INTELIGENCIA ARTIFICIAL Y DERECHO}

\section{Breve introducción a la inteligencia artificial aplicada al derecho}

Las investigaciones interdisciplinarias llevadas a cabo con el objetivo de desarrollar aplicaciones de inteligencia artificial en el 
Este libro forma parte del acervo de la Biblioteca Juridica Virtual del Instituto de Investigaciones Juridicas de la UNAM

campo del derecho son denotadas con la expresión "inteligencia artificial aplicada al derecho" (Artificial Intelligence and Law o AI and Law). ${ }^{31}$

En los países de habla hispana es considerada como una rama de la informática jurídica decisional. Sin embargo, existen algunas dificultades para restringir este tipo de investigación al modelado de decisiones, como poner de relieve las investigaciones tendentes a hacer que la computadora produzca resúmenes automáticos de textos jurídicos digitalizados, y de esa manera genere propuestas de teorías jurídicas, o el desarrollo de metodologías para la representación del conocimiento jurídico mediante la elaboración de ontologías jurídicas.

Dadas sus particulares características y que actualmente está involucrando de modo importante al conocimiento proveniente de la teoría general del derecho, la epistemología jurídica, la filosofía del derecho, etcétera, puede considerarse como un dominio híbrido aparte, sin perder su vinculación con el concepto central de informática jurídica.

No obstante, es cierto que uno de los temas centrales de la inteligencia artificial aplicada al derecho ha sido la emulación del razonamiento jurídico. Es así que durante la década de los ochenta predominaron los proyectos tendentes a desarrollar sistemas expertos jurídicos (SEJs). La expresión "SEJ" denota al sistema computacional capaz, por una parte, de reportar un comportamiento semejante al de los expertos (humanos) en algún área de la actividad técnica-jurídica, como el de un juez en el procedimiento de resolución de controversias, o el de un abogado al otorgar asesoría jurídica y, por otra, de explicar las pautas de razonamiento empleadas para la solución del problema planteado. ${ }^{32}$

A diferencia de los sistemas jurídicos de recuperación documental (Legal Information Retrieval Systems) que almacenan información jurídica y facilitan su consulta automatizada, un SEJ pre-

31 Aguilera García, Edgar, Inteligencia artificial aplicada al derecho, México, UNAM, Instituto de Investigaciones Jurídicas, 2007, p. 43.

32 Ibidem, p. 45. 
Este libro forma parte del acervo de la Biblioteca Juridica Virtual del Instituto de Investigaciones Juridicas de la UNAM

tende emular algunos de los procesos cognitivos llevados a cabo por los operadores jurídicos en los procedimientos de creación, interpretación y aplicación del derecho. ${ }^{33}$

En la actualidad, se desarrollan aplicaciones que asumen tanto el denominado "modelo de procesamiento simbólico", v. g., sistemas expertos jurídicos (SEJs), como el "modelo conexionista", v. g., redes neuronales jurídicas, o bien, ambos, para crear los llamados "sistemas híbridos".

Para complementar el panorama de tópicos que hoy en día se investigan bajo el rótulo de "inteligencia artificial aplicada al derecho", John Zeleznikow ${ }^{34}$ propone los siguientes dominios:

A) Desarrollo de sistemas que facilitan la comprensión y aplicación de la compleja información contenida en fuentes legislativas. ${ }^{35}$

B) Representación y razonamiento con conceptos jurídicos de textura abierta.

C) Desarrollo de ontologías jurídicas para mejorar el desempeño de los motores de búsqueda en la recuperación de información jurídica, así como para tratar de uniformar el lenguaje jurídico en la red mundial (World Wide Web o $W W W$ ). En el terreno del desarrollo y utilización de las ontologías jurídicas como una técnica para la representación del conocimiento jurídico, vale destacar la investigación realizada por el licenciado Edgar Aguilera dentro

33 Idem.

34 Zeleznikow, John, "Split-Up. A Web-Based Legal Decision-Support System that Advices upon the Distribution of Marital Property", en Cáceres Nieto, Enrique (coord.), Inteligencia artificial aplicada al derecho. Memoria del Congreso Internacional de Culturas y Sistemas furídicos Comparados, México, UNAM, 2005, p. 182.

35 Por ejemplo, la tecnología de bases de reglas legislativas (Legislative $\mathrm{Ru}$ lebase Technology) diseñada por SoftLaw para fomentar la eficiencia en el desempeño de las instituciones gubernamentales, a partir de la generación de versiones easy-to-use de textos legislativos, que facilitan a sus operadores su comprensión y aplicación. 
Este libro forma parte del acervo de la Biblioteca Juridica Virtual del Instituto de Investigaciones Juridicas de la UNAM

del marco del proyecto "Sistemas expertos para la ayuda a la decisión judicial" del Instituto de Investigaciones Jurídicas de la UNAM. ${ }^{36}$

D) Desarrollo de sistemas de asesoría jurídica (Legal Advisory Systems). ${ }^{37}$

E) Sistemas de apoyo a la decisión jurídica (Legal Decisión Support Systems). ${ }^{38}$

F) Desarrollo, mediante el empleo de técnicas de inteligencia artificial como la "minerología de datos", de sistemas de recuperación y tratamiento de documentación jurídica (Legal Document Management and Retrieval Systems). ${ }^{39}$

G) Desarrollo de sistemas para la Argumentación y Negociación Jurídica. ${ }^{40}$

H) Tutores inteligentes. ${ }^{41}$

Los principales foros en los que se presentan y discuten los avances de la comunidad estructurada para llevar a cabo esta clase de investigaciones son:

36 Aguilera, Edgar, La necesidad de aplicar las ontologías en el desarrollo de sistemas expertos jurídicos, Tesis de licenciatura en Derecho.

37 Por ejemplo, el sistema Split-Up que asesora sobre la forma más probable en que se distribuirán los bienes luego de la disolución del vínculo matrimonial, desarrollado por el propio Zeleznikow.

38 Por ejemplo, el sistema Get Aid en Australia, capaz de predecir el posible resultado de una controversia jurídica y determinar así, si una solicitud de asistencia legal procede o no. O el sistema "Justiniano", prototipo de sistema experto para la ayuda a la calificación de hechos violatorios de derechos humanos desarrollado por el doctor Cáceres en el Instituto de Investigaciones Jurídicas de la UNAM.

39 Por ejemplo, los sistemas australianos Datalex y FlexLaw.

40 Por ejemplo, el trabajo paradigmático desarrollado por Henry Prakken y Bart Verheij en Holanda.

41 Por ejemplo, el sistema CATO desarrollado por Kevin Ashley en Pittsburg, el cual presenta ejercicios a los estudiantes, los cuales incluyen los hechos del caso, un conjunto de precedentes en línea, e instrucciones acerca de cómo argumentar o contrargumentar. 
Este libro forma parte del acervo de la Biblioteca Juridica Virtual del Instituto de Investigaciones Juridicas de la UNAM

A) Conferencia internacional sobre inteligencia artificial y derecho (International Conference on Artificial Intelligence and Law, o ICAIL). ${ }^{42}$

B) La fundación para los sistemas jurídicos basados en el conocimiento (JURIX). ${ }^{43}$

C) Revista "Inteligencia artificial y derecho" (AI and Law Journal). ${ }^{44}$

En el ámbito latinoamericano se ha iniciado la incursión en esta novedosa área implementando una coordinación de investigación en inteligencia artificial aplicada al derecho en el Instituto de Investigaciones Jurídicas de la Universidad Nacional Autónoma de México de la que tengo el honor de ser responsable y en donde se está llevando a cabo el multicitado proyecto que a continuación presento.

\section{El Proyecto Conacyt 42163-S "Sistemas expertos}

para la ayuda a la decisión judicial"

Desde hace tres años, en el Instituto de Investigaciones Jurídicas de la UNAM y, a instancias de su entonces director, el doctor Diego Valadés, sin cuyo constante apoyo la inteligencia artificial aplicada al derecho no existiría en nuestro país, se inició un proyecto tendente a auxiliar a jueces no expertos en materia de juicios por pensión alimenticia, mediante la simulación de los procesos de razonamiento que tienen lugar entre jueces expertos.

En el desarrollo del mismo, ha sido fundamental el apoyo del Tribunal Superior de Justicia del Estado de Tabasco, quien, gracias al impulso de su presidente, el licenciado Guillermo Nar-

\footnotetext{
42 Se puede consultar en línea en: http://wrwr.iaail.org/icail-2007/index.html.

43 Se puede consultar en: $h t t p: / /$ wrew.jurix.nl/index.php?option $=$ content E'task $=v$ iew $\Xi i d=22$ EItemid $=2$.

44 Disponible en: http://wrerr.ingentaconnect.com/content/klu/arti.
} 
Este libro forma parte del acervo de la Biblioteca Juridica Virtual del Instituto de Investigaciones Juridicas de la UNAM

váez, se ha llegado a constituir como un tribunal modelo por su grado de automatización y eficiencia. ${ }^{45}$

El proyecto continúa en marcha, y la presente contribución forma parte del proceso de investigación.

Durante siete meses se ha trabajado arduamente con jueces, magistrados, profesores y abogados postulantes, a efecto de desarrollar una teoría con bases constructivistas que refleje la forma en que efectivamente toman sus decisiones los impartidores de justicia.

El producto final consistirá en un sistema inteligente capaz de hacer sugerencias a los jueces no expertos para que puedan decidir como lo hacen los expertos en la materia.

Las ventajas de ello son múltiples y redundan directamente en la calidad de la impartición de justicia, pero también tiene importantes consecuencias económicas si se consideran los gastos implicados en sucesivas impugnaciones originadas en decisiones técnicamente incorrectas.

El desarrollo del proyecto ha contado con el apoyo de los más grandes especialistas de la comunidad internacional ${ }^{46}$ y sus resultados provisionales han sido discutidos y revisados en los principales foros internacionales.

La implementación del sistema experto significará, para nuestro país, haber logrado tener la primera aplicación de un sistema real en su género a nivel mundial y contar con los desarrollos teóricos y metodológicos necesarios para la generación de futuros sistemas que contribuyan no sólo a aumentar la calidad de las decisiones y a reducir los costos de operación del aparato jurisdiccional, sino también a abatir la corrupción.

45 El portal del Tribunal Superior de Justicia de Tabasco puede consultarse en: http://wwre.tsj-tabasco.gob.mx.

46 Tales como Kevin D. Ashley, presidente de la revista Artificial Intelligence and Law Fournal, Burkhard Schaffer del Joseph Bell Centre for Forensic Statistics and Legal Reasoning de Escocia, Trevor Bench-Cappon de la Universidad de Liverpool, Radboud Winkels, director del Leibniz Centre for Law en Holanda, Tom Van Engers, organizador de la más reciente conferencia de la fundación JURIX para el conocimiento jurídico y los sistemas de información, en París en 2006. 
Este libro forma parte del acervo de la Biblioteca Juridica Virtual del Instituto de Investigaciones Juridicas de la UNAM http://www.juridicas.unam.mx

Libro completo en

http://biblio.juridicas.unam.mx/bjv

https://goo.gl/6JeUWd 
Este libro forma parte del acervo de la Biblioteca Juridica Virtual del Instituto de Investigaciones Juridicas de la UNAM

\section{CAPÍtulo SEgundo \\ MARCO TEÓRICO}

\section{TÉGNICAS ERIGKSONIANAS PARA LA ELICITACIÓN DEL GONOCIMIENTO JUDICIAL COMPILADO}

\section{Noción de conocimiento compilado en ingeniería del conocimiento}

Uno de los conceptos centrales en la elaboración de sistemas expertos es el de conocimiento compilado, mismo que es definido como "el proceso de «encapsular» el conocimiento; o sea, agrupar como unidades funcionales o «cuantos» partes significativas del conocimiento que, como tales unidades son almacenadas y recuperadas". ${ }^{47}$

El proceso mediante el cual el conocimiento es "encapsulado", implica dos formas complementarias. La primera se deriva de lo que podría llamarse "conocimiento público", proveniente de la transferencia de la información contenida en fuentes formales de conocimiento, como es el caso de los libros, los artículos científicos, definiciones, explicaciones, etcétera. Por lo que corresponde al derecho, los insumos vendrían a ser las leyes, los códigos, los libros de doctrina, los de teoría del derecho, la jurisprudencia, etcétera.

La segunda forma de conocimiento es el denominado "heurístico", resultante de la experiencia que está organizada en la memoria episódica, misma que, a través de procesos de induc-

47 Adarraga, Pablo y Zaccagnini, José Luis, Psicología e inteligencia artificial, España, Trotta, 1994. 
Este libro forma parte del acervo de la Biblioteca Juridica Virtual del Instituto de Investigaciones Juridicas de la UNAM

ción analógica, produce generalizaciones en la memoria semántica y queda indexada en la memoria a largo plazo para poder ser utilizada y adaptada para afrontar nuevos problemas o situaciones mediante procesos retro-proyectivos.

Un ejemplo del primer tipo de conocimiento tiene lugar durante la fase de estudios teóricos en las universidades y, del segundo, en el que poseen los expertos como resultado de años de práctica.

A diferencia de lo que ocurre con el conocimiento académico, que suele ser explicito, e incluso, "recitado" a voluntad, el conocimiento heurístico radica en el inconsciente y, por tanto, no puede ser explicitado fácilmente por el propio experto quien, en algún sentido, puede decirse que sabe que lo tiene, aunque no sepa en qué consiste exactamente, ni pueda explicitarlo con precisión. Es el tipo de conocimiento que está presente en un terapeuta experto que de un simple golpe de vista, sabe qué tipo de padecimiento aqueja a su paciente, o en el abogado experto para quien son suficientes unos cuantos datos acerca de los hechos de un caso para identificar la estrategia que seguirá durante el litigio. Es ese conocimiento que subyace cuando, ante la pregunta formulada a genios como Erickson o Satir acerca de ¿cómo hacen lo que hacen?, seguiría la respuesta perplejante: ¡No sé, simplemente lo hago!

Para el desarrollo de un sistema experto judicial, el conocimiento heurístico presupone al de tipo académico y obtenerlo constituye una de las piezas claves para el éxito del proyecto.

Sin embargo, el problema que se presenta es ¿cómo obtener de jueces expertos ese conocimiento que ellos mismos no pueden identificar con claridad y menos explicitarlo? Ello lleva al problema central de esta investigación: el de la elicitación del conocimiento judicial.

\section{El conocimiento compilado como teoría implícita}

A efecto de caracterizar con mayor precisión al conocimiento compilado es posible considerarlo como una clase de 
Este libro forma parte del acervo de la Biblioteca Juridica Virtual del Instituto de Investigaciones Juridicas de la UNAM

"teoría implícita", concepto de sumo interés en los ámbitos de la ingeniería del conocimiento y de la psicología educativa contemporáneas.

Algunas referencias representativas de los logros obtenidos en el terreno del estudio de teorías implícitas son las siguientes. ${ }^{48}$ En su interesante trabajo "Implicit Theories, Goal Orientations, and Perceived Competence: Impact on Students' Achievement Behavior", Angeliki Leondari (University of Thessaly) y Vasilios Gialamas (Athens University) ${ }^{49}$ arroja luces sobre el papel motivacional que desempeñan las teorías implícitas que sobre la inteligencia tienen los estudiantes de primaria y secundaria.

Las dos teorías identificadas fueron denominadas por los investigadores como la Entity Theory y la Incremental Theory. La primera implica una concepción estática de la inteligencia. Ésta es vista como una entidad inmutable. Mientras la segunda implica una concepción dinámica, según la cual, la inteligencia es vista como un conjunto de habilidades susceptible de incrementar y mejorar con el adiestramiento adecuado.

La importancia de identificar dichas teorías es que se vinculan directamente con cuestiones como el esfuerzo académico y con las ganas de enfrentar retos intelectuales. Quienes sostienen la primer teoría se preocupan más por su éxito académico, por lo que tratan de evitar tareas en las que su desempeño pueda ser evaluado pobremente. Los que sostienen la segunda manifiestan un esfuerzo progresivo de acuerdo con el incremento en la dificultad de la tarea o problema, siendo su interés comprenderlo, más que ser evaluados exitosamente.

48 Nuevamente agradezco la invaluable colaboración de mi asistente principal de investigación, el licenciado Edgar Aguilera García, para el desarrollo de esta sección del trabajo.

49 Leondari, Angelik y Gialamas, Vasilios, "Implicit Theories, Goal Orientations, and Perceived Competence: Impact on Students' Achievement Bahavior", Psychology in the Schools, vol. 39(3), 2002, publicado en línea en Wiley InterScience en: wrwe.interscience.wiley.com. 
Este libro forma parte del acervo de la Biblioteca Juridica Virtual del Instituto de Investigaciones Juridicas de la UNAM

En otro estudio titulado "Implicit Theories and Conceptions of Morality", ${ }^{50}$ Chi-yue Chiu (University of Hong Kong), Carol S. Dweck (Columbia University), Jennifer Yuk-Yue Tong y Jeanne Jo-Ying Fu (University of Hong Kong), sostienen la tesis general de que las creencias morales de los individuos están determinadas por las teorías implícitas que éstos tienen acerca de la realidad social en que se encuentran inmersos.

En forma específica, la hipótesis es que quienes mantienen una concepción estática y externalista de la realidad (teoría de la realidad como entidad, o Entity Theory) tienden a organizar su sistema de creencias morales desde un enfoque de "deberes" u "obligaciones", mientras que para los que consideran que la realidad social tiene un carácter esencialmente dinámico (teoría incrementalista, o Incrementalist Theory), los derechos (morales) desempeñan un papel central en su sistema de creencias.

El estudio presupone la clasificación de Dworkin respecto de las creencias morales: las basadas en deberes y las basadas en derechos. La justificación moral de las conductas, para el caso de quienes sostienen primordialmente las primeras, es un asunto de verificar si los agentes involucrados en la situación en cuestión han actuado en cumplimiento o no de los deberes prescritos por "el orden moral", el cual, desde esta perspectiva, es visto como absoluto e inmutable:

...when individuals believe that they live in a fixed reality with a rigid moral order, perhaps the most important criterion for deciding the morality of a state of affairs is whether the moral agents (people and social institutions) have carried out the duties prescribed by the existing moral order. ${ }^{51}$

La preocupación central de quienes sostienen creencias de la segunda clase consiste en buscar e identificar principios (como el

50 Chiu, Chi-yue et al., "Implicit Theories and Conceptions of Morality", Fournal of Personality and Social Psychology, vol. 73, núm. 5, 1997, pp. 923-940.

51 Idem. 
Este libro forma parte del acervo de la Biblioteca Juridica Virtual del Instituto de Investigaciones Juridicas de la UNAM

respeto a los derechos humanos) en torno a los cuales la realidad deba ser moldeada. Para ellos, la autoridad del orden moral no es más ya absoluta:

However, when individuals believe that the world they live in is malleable, they may instead seek principles in terms of which the world should be shaped. That is, the authority of the existing moral order is no longer absolute, and one's duty with in it is not the primary concern. Instead to them the primary concern would be to identify, work toward, and uphold principles that will guide the society and its moral agents. ${ }^{52}$

Otro aspecto que hay que resaltar respecto a la moralidad basada en deberes es que está íntimamente vinculada con la permanencia del statu quo.

Por su parte, la moralidad basada en derechos es concebida como un motor del cambio social. Al respecto, considérese lo siguiente:

When one believes in a fixed social-moral reality, one may invest in the status quo, and one's moral orientation would be toward supporting the status quo... By contrast when one believes in a more dynamic, malleable social-moral reality, one should be oriented toward moral beliefs that allow and support changes. Whereas duty-based morality is a system-oriented morality that serves to maintain the status quo, rights-based morality is a person-centered morality that promotes social change. ${ }^{53}$

De igual forma un tercer trabajo digno de ser mencionado es "Implicit Theories of Relationships: Assessment and Prediction of Romantic Relationship Initiation, Coping and Longevity", 54 realizado por C. Raymon Knee (University of Houston).

52 Idem.

53 Idem.

54 Knee, Raymond, "Implicit Theories of Relationships. Assessment and Prediction of Romantic Relationship Initiation, Coping, and Longevity", fournal of Personality and Social Psychology, vol. 74, núm. 2, 1998, pp. 360-370. 
Este libro forma parte del acervo de la Biblioteca Juridica Virtual del Instituto de Investigaciones Juridicas de la UNAM

En este estudio se analizan las implicaciones que conlleva sostener dos teorías implícitas sobre la naturaleza de las relaciones sentimentales. De un lado están aquellos que creen en el destino y consideran que una pareja debe perdurar sólo si las partes están hechas la una para la otra (teoría del destino, o Destiny Theory). De otro, quienes sostienen que las relaciones sentimentales exitosas maduran gradualmente y requieren ser cultivadas y cuidadas (teoría de la madurez, o Growth Theory).

Puede decirse que quienes creen en el destino generalmente también creen lo siguiente:

a) Sólo hay una pareja romántica para cada persona

b) La persona amada satisfará los más altos ideales

c) Se debe seguir el corazón en lugar de la mente al elegir una pareja

Por ello, la hipótesis es que quienes asumen esta perspectiva pondrán un mayor énfasis en las impresiones iniciales de la relación, en qué tanta compatibilidad se experimente con la pareja, aun cuando la relación esté en sus comienzos y no se tenga un repertorio más o menos amplio de experiencias conjuntas. En este sentido, puede esperarse que una vez hecho un juicio de incompatibilidad en estas primeras etapas, la persona decida no continuar más adelante y terminar la relación.

Por su parte, se espera que quienes sostienen la segunda teoría tengan una actitud más comprometida, una que requiere de esfuerzo y de la superación de obstáculos con el fin de obtener un mayor grado de cercanía con la pareja:

...those who believe that relationships are destined may be sensitive to early indications that they can not succeed at the relationship and thus, may similarly tend to give up easily. In this way believe in destiny may place heavy emphasis on impressions of success during incipient stages of the relationship, whereas belief in growth may weigh initial impressions of compatibility less heavily, emphasizing the more dynamic facets of understanding, 
Este libro forma parte del acervo de la Biblioteca Juridica Virtual del Instituto de Investigaciones Juridicas de la UNAM

development, and closeness... Thus, belief in destiny... emphasizes the importance of initial compatibility and may lead one to search for the one perfect mate or perhaps discard less-than-perfect candidates relatively quickly. A growth theory of relationships embodies a different (but not opposite) view of how successful relationships come to be. Conceptually a growth theory of relationships holds that successful relationships are constructed and developed by conquering obstacles and growing closer. $^{55}$

Una última investigación sobre teorías implícitas altamente relevante para los efectos de este trabajo es expuesta en el artículo "Implicit Theories about Everyday Problem Solving", ${ }^{56}$ presentado en la conferencia anual (1993) de la Asociación Americana de Investigación Educativa (Annual Meeting of the American Educational Research Association) por Herbert y Jean-Paul, quienes se dan a la tarea de investigar las teorías implícitas que personas adultas entre los veinicinco y los sesenta años tienen acerca de la resolución de problemas de la vida cotidiana (Everyday Life Problem-Solving).

\section{A. Presupuestos de la investigación}

Algunos de ellos son los siguientes:

A) Es importante considerar el elemento contextual en la resolución de problemas cotidianos:

Neisser emphasizes the contextual element of appropriate intelligent behavior, "intelligent behavior in real settings often involves actions that satisfy a variety of motives at once - practical and interpersonal ones, for example - because opportunities to satisfy them appear simultaneously. It is often accompanied by emotions

\section{Idem.}

56 Herbert, Margaret y Dionea, Jean Paul, "Implicit Theories About Everyday Problem-Solving", presentado en la Annual Meeting of the American Educational Research Asociation, Atlanta, 1993. 
Este libro forma parte del acervo de la Biblioteca Juridica Virtual del Instituto de Investigaciones Juridicas de la UNAM

and feelings, which is appropriate in situations that involve other people...".57

B) Puede evidenciarse la aplicación del pensamiento creativo aún en las actividades (problemas) más ordinarias: "Creative thought and problem solving are evident even in such seemingly mundane situations as making tea". ${ }^{58}$

C) La habilidad para resolver problemas de la vida cotidiana se incrementa con la edad, y el grado de eficiencia en la resolución de problemas cotidianos generalmente no está relacionado con el nivel de estudios de los sujetos: "They (Cornelious and Caspi) found that performance on the Everyday Problem-Solving Inventory, traditional verbal ability measures increased with age, and that the level of education was unrelated to everyday problem solving ability". ${ }^{59}$

D) Toda una serie de elementos subjetivos, tales como la historia de éxitos y fracasos, el estrés, diferentes motivaciones, experiencias pasadas, hábitos adquiridos, personalidad, preferencias personales, etcétera, se convierten en variables que determinan la solución por la que se opta al resolver un problema:

...Adults make decisions daily on the basis of what they believe, how they feel, their level of motivation, their insight into their own knowledge base and the operative situational variables... Adults bring a particular predisposition to the learning situation... The prior knowledge, experience, habitual responses, broader life context, differing motivational and attributional orientations, history of success or failure, personality, stress, social and cognitive factors, fear-of-failure, etcétera, which they bring to the problem space can all result in endlessly confounding variables within the learning context. ${ }^{60}$

\footnotetext{
57 Idem.

58 Idem.

59 Idem.

60 Idem.
} 
Este libro forma parte del acervo de la Biblioteca Juridica Virtual del Instituto de Investigaciones Juridicas de la UNAM

E) El llamado "conocimiento metacognitivo" desempeña un papel fundamental en el monitoreo, coordinación y control de las estrategias para resolver problemas:

The effective management of information and resources for the achievement of a targeted goal is enabled by a group of abilities referred to as metacognition. These processes involve the predicting, checking, monitoring, reality testing, coordination and control of deliberate attempts to learn or solve problems. Metacognitive knowledge is essentially knowledge or beliefs about what factors or variables act or interact in such fashions as to affect the course and outcomes of cognitive endeavors. These variables involve those of person, task and their interactions... Much of the considerable body of research by Pressley (1989) and his colleagues is predicated on the assumption that individuals hold general beliefs about the factors which affect their performance and determine their own competence. ${ }^{61}$

F) El sujeto generalmente no es consciente del papel que juega el conocimiento meta-cognitivo:

...Whether intentionally or unintentionally activated, metacognitive knowledge has an influence on cognitive processes in problem solving without it necessarily entering consciousness. Once it has done so then it becomes a metacognitive experience (Flavell, 1979). It is the challenge of the present research to attempt to uncover and illuminate the findings of such complex thought processes about which the participants may have little conscious awareness. ${ }^{62}$

G) La aplicación de conocimiento heurístico previamente desarrollado por el individuo, puede declinar a favor de metodologías más intuitivas, e incluso emotivas e impulsivas:

...Many solutions to problems in everyday life are chosen on the basis of emotions, values, beliefs, insights, "feelings of knowing",

61 Idem.

62 Idem. 
Este libro forma parte del acervo de la Biblioteca Juridica Virtual del Instituto de Investigaciones Juridicas de la UNAM

or may even be impulsive responses rather than predictable, logical progressions through identifiable stages. Heuristics known, and indeed often applied by the individual, may be thrown aside at any time in favor of these subjective elements. ${ }^{63}$

H) Los problemas de la vida cotidiana (como el caso de los que enfrentan los jueces), son de los llamados "no definidos" o ill-defined:

...the genre of problems facing daily living are invariably ill-defined... Problems are considered ill-defined when the representations of one of the more basic components (the goal, initial state, operators, and constraints) are incomplete (Halyoak, 1990)... Hayes (1981) distinguishes an ill-defined problem as one requiring the solver to contribute to the definition of the problem from him/her own repertoire of resources. As the information necessary to solve the problem is not fully contained within the problem space, there are no simple paths for solution. Action must be taken within an atmosphere of uncertainty. ${ }^{64}$

\section{B. Inducción y problemas no-definidos (el modelo de Holland, Holyoak y Nisbett)}

Los autores del estudio adoptan el modelo que proporcionan Holland, Holyoak y Nisbett para explicar la forma en la que se afrontan los problemas no definidos, característicos de la vida cotidiana. Se trata de un modelo inductivo para el cual las excepciones y las constantes modificaciones o variaciones de los métodos de solución son elementos integrales. En este sentido, los autores explican que:

...Induction refers to all inferential processes that expand knowledge in the face of uncertainty (Holland et al. p. 1). Induction

\footnotetext{
63 Idem.

64 Idem.
} 
Este libro forma parte del acervo de la Biblioteca Juridica Virtual del Instituto de Investigaciones Juridicas de la UNAM

then, is the study of how knowledge is modified through its use. Individuals formulate categories as they generate goal-relevant inferences. The relevance and validity of what the learner brings to the problem environment will either enhance or retard this inductive process. ${ }^{65}$

\section{Tipos de conocimiento dentro del modelo}

El modelo clasifica el conocimiento en tres grandes categorías, a saber:
A) Declarative knowledge (required factual information)
B) Procedural knowledge ("how" to perform the task or im- plement the solution), and
G) Conditional knowledge ("when" to apply which procedure).

\section{Los modelos mentales o teorías implícitas}

La generación y/o revisión de "modelos mentales" o teorías implícitas es una función fundamental en el modelo aludido. Los autores explican que:

...Holyoak specifies that the activity of problem finding, defining, and refining resurrects old knowledge in such a way as to generate new possibilities, via the construction of mental models. Such models are a psychological representation of a given environment and its expected behavior. This mental model is then used to predict the results of possible changes in the external environment. Depending upon the nature of the problem, and the problemsolver, model construction may be thorugh morphisms, homomorphisms, isomorphisms, analogies, metaphors, and schemas. Induction then, is the process whereby mental models are generated and the components of which are revised... ${ }^{66}$ 
Este libro forma parte del acervo de la Biblioteca Juridica Virtual del Instituto de Investigaciones Juridicas de la UNAM

\section{E. Investigación empirica de modelos mentales/teorías implícitas (elicitación del conocimiento)}

Los autores hacen el siguiente reconocimiento: "Mental models or implicit theories already exist in peoples' minds (Sternberg et al., 1981). They require that the researcher discover them, by eliciting their form and content through a sensitive and flexible methodology".

El estudio de teorías implícitas resulta sumamente relevante para la comprensión del conocimiento compilado. Algunas de las conclusiones que se siguen de ellas son la siguientes: 1) Puede haber teorías implícitas diferentes acerca de un mismo aspecto del mundo, del mismo modo que jueces diferentes pueden tener teorías implícitas diferentes acerca de la manera de resolver cierto caso; 2) Las teorías implícitas son el presupuesto que determina las actitudes, comportamientos e, incluso, emociones de quienes las sustentan, lo cual se suele poner de relieve en el sesgo con que se resuelven casos penales que involucran cuestiones de género; 3) Las teorías implícitas juegan un papel fundamental en la manera de resolver problemas no definidos, característicos de la vida cotidiana, pero también el tipo de problemas que deben enfrentar los jueces ante un caso sobre el que deben dictar una sentencia, y 4) La elicitación de las teorías implícitas constituye la vía empírica para estudiarlas científicamente y, por tanto, modelarlas.

En el ámbito de la experiencia terapéutica es posible reencuadrar muchos fenómenos tales como las creencias limitantes, los disfraces, la desesperanza aprendida, etcétera, como clases de teorías implícitas.

En el terreno judicial, dichas teorías pueden ser de carácter estrictamente técnico, por ejemplo, tener la teoría implícita de que decirle "gorda" a la esposa constituye una injuria a una mujer con antecedentes de depresión por baja autoestima y, por tanto, es una causal de divorcio; o también pueden ser de índole estrictamente idiosincrásica; sin embargo, con consecuencias jurídicas, como ocurre en el caso de los prejuicios étnicos. 
Este libro forma parte del acervo de la Biblioteca Juridica Virtual del Instituto de Investigaciones Juridicas de la UNAM

A pesar de que la literatura de la ingeniería del conocimiento no considera expresamente al conocimiento compilado a la luz de la teoría de las teorías implícitas, en este trabajo se considera que dicha caracterización resulta sumamente fructífera para explicar y, sobre todo, tratar de simular la forma de procesar información y se toman decisiones por parte de jueces expertos.

\section{Construcción autoorganizativa del conocimiento compilado}

\section{A. El conocimiento compilado y la "parte sabia" ericksoniana}

Uno de los conceptos centrales en la formación ericksoniana, si no es que el central, suele ser denotado con términos tales como "parte sabia", "yo soy yo", "Dios en mí mismo", etcétera. Desde las primeras sesiones de la capacitación psicoterapéutica se nos enseña a entrar en contacto con ella y se explica que sin que hagamos nada es la que está a cargo de muchísimas de las funciones vitales de nuestro organismo y de nuestra vida psíquica. Algunas de las tareas que esta extraordinaria "parte sabia" realiza por nosotros son: aprender a caminar, a conjugar correctamente los verbos mucho antes de aprender gramática en la escuela, realizar nuestras primeras categorizaciones conceptuales mucho antes de tomar clases de lógica, etcétera.

A pesar de que no se suele referir expresamente, parece innegable que esa "parte sabia" es también responsable de la elaboración de nuestras teorías implícitas y, por tanto, de nuestro conocimiento compilado, tanto del heurístico puro o derivado de nuestras experiencias de vida, como del profesional o experto.

El núcleo de esta investigación radica, precisamente, en asumir que, de la misma forma que nuestra "parte sabia" se ocupa de compilar y mantener fuera del alcance consciente a nuestro conocimiento compilado, con un empleo adecuado de las técnicas ericksonianas, es posible acceder al mismo y hacer que el conocimiento desarrollado a lo largo de años de experiencia y pericia de expertos en diferentes campos, incluyendo, desde luego, 
Este libro forma parte del acervo de la Biblioteca Juridica Virtual del Instituto de Investigaciones Juridicas de la UNAM

a los funcionarios judiciales, pueda ser explicitado a efecto de ser representado y transmitido mediante la enseñanza o, como es el caso de la investigación en que se circunscribe este trabajo, simulado a través de un programa de cómputo.

\section{B. Breve comentario sobre la "parte sabia" y el paradigma} de la fisica cuántica

Dada la importancia de la "parte sabia" en los procesos de formación del conocimiento compilado, es indispensable preguntarse acerca de la forma adecuada de explicar cómo opera.

Una de las alternativas propuestas por la doctora Robles consiste en la posibilidad de considerar a dicha "parte sabia" como un explanandum, susceptible de ser abordado desde la teoría proporcionada por la física cuántica.

Lo que a continuación expongo son algunas de las razones por las cuales considero que, aunque es sumamente sugerente, es prematuro afirmar dicha alternativa. Ello me sirve de justificación para proponer un marco teórico de índole meramente conceptual y, por tanto, deliberadamente precientífico.

Tal como la propia doctora Robles ${ }^{67}$ sostiene y yo mismo he suscrito en mi artículo "Las teorías jurídicas como realidades hermenéuticas", ${ }^{68}$ las teorías constituyen esquemas, prismas que determinan nuestra manera de percibir, comprender e interactuar con lo que consideramos realidad a partir de ellas.

Sin embargo, uno de los problemas básicos que caracteriza a la filosofía posmoderna, estriba en su pretensión de pasar por alto que no todo esquema puede ser válido como generador de conocimiento, a pesar de determinar la realidad de quien lo suscribe.

67 Robles, Teresa, Concierto para cuatro cerebros en psicoterapia, México, Alom Editores, 2001.

68 Cáceres, Enrique, "Las teorías jurídicas como realidades hermenéuticas", Boletín Mexicano de Derecho Comparado, México, nueva serie, año XXXV, núm. 103, enero-abril de 2002. 
Este libro forma parte del acervo de la Biblioteca Juridica Virtual del Instituto de Investigaciones Juridicas de la UNAM

De operar bajo esa óptica, se presentarían problemas de difícil solución, como es el consistente en no poder distinguir entre la realidad proporcionada por la cosmovisión del mundo producida por un sistema de creencias religiosas, y las concepciones del mundo derivadas de las teorías científicas.

Es decir, del hecho de que el empirismo haya sido derrumbado por el constructivismo y con él conceptos tales como el de verdad, realidad u objetividad absolutas, no se sigue que las concepciones científicas y otras, como las mitológicas, se encuentren en un mismo plano de justificación epistemológica.

Aun asumiendo que las teorías científicas no son sino constructos, es necesario reconocer que las explicaciones que producen son el resultado de reglas de procesamiento de la información privilegiadas, con un rigor especial y mecanismos de validación estrictos.

Esto significa que sostener que un cierto fenómeno puede ser explicado desde un paradigma científico implica que dichas explicaciones puedan ser alcanzadas con las reglas de procesamiento y validación del propio paradigma (método científico) y la teoría de la verdad correspondiente.

Una de las grandes incógnitas actuales es si los estados amplificados de consciencia, inducidos a partir de las técnicas ericksonianas, pueden considerarse o no objeto de explicación por parte de la física cuántica.

$\mathrm{Al}$ respecto, respondo que, al menos en el estado actual, no es posible afirmarlo dada la complejidad de las dimensiones tanto subsimbólica como simbólica que los caracterizan. Expresado en otros términos, dichos estados son tan complejos que ni aún la física cuántica puede dar cuenta de ellos y su abordaje científico es aún insospechado.

Las razones que justifican esta afirmación son las siguientes:

Cómo es bien sabido, el ideal de la física consiste en

...que alguna vez se desarrolle una teoría completa, en el sentido de que contenga en su formalismo una representación para todos los elementos relevantes de la realidad física, y concluida, en el 
Este libro forma parte del acervo de la Biblioteca Juridica Virtual del Instituto de Investigaciones Juridicas de la UNAM

sentido de que todos los aspectos de su formalismo tengan una interpretación clara y sin ambigüedades, y sea aplicable a todos los sistemas físicos, pudiendo predecir comportamientos que se corroboren experimentalmente. ${ }^{69}$

La elaboración de tal teoría unificadora, conocida con el nombre de "teoría de las supercuerdas", ocupó treinta años de la vida de Einstein y no tuvo resultados exitosos.

En el estado actual, la física tiene que conformarse con cuatro diferentes teorías, cada una de las cuales es apta para ciertos tipos de sistemas físicos.

La mecánica clásica es adecuada para dar cuenta de sistemas físicos de tipo corpuscular, constitutivos de los datos sensoriales que configuran nuestras intuiciones generales acerca de lo que los realistas suelen denotar con el término "realidad externa". Es característico de dichos sistemas contar con partículas cuya masa o energía se desplaza bastante por debajo de la velocidad de la luz.

Sin embargo, la mecánica clásica no puede explicar ni predecir satisfactoriamente el comportamiento de sistemas físicos cuya materia o energía se desplazan cerca de la velocidad de la luz (como es el caso de los fotones). La teoría que da cuenta de los mismos, es la mecánica relativista, la cual puede ser útil para explicar a los sistemas físicos que son objeto de la mecánica clásica, pero no a la inversa.

A pesar de sus importantes diferencias, ambas mecánicas, la clásica y la clásica relativista, satisfacen la virtud epistémica consistente en contar con un sólido formalismo que, además, cuenta con una interpretación clara, ampliamente aceptada y sin ambigüedades.

Por su parte, la mecánica cuántica ha tenido grandes éxitos en la explicación y predicción del comportamiento de muchos sistemas físicos constituidos por materia o energía con velocidades pequeñas y una acción próxima a la constante de Planck.

69 Torre, Alberto Clemente de la, Física cuántica para filo-sofos, México, Fondo de Cultura Económica, 2000. 
Este libro forma parte del acervo de la Biblioteca Juridica Virtual del Instituto de Investigaciones Juridicas de la UNAM

Para aquellos sistemas que requieren de un tratamiento cuántico y relativista, se cuenta con la mecánica clásica relativista.

Sin embargo, a pesar de sus impresionantes resultados en materia de desarrollo de semiconductores y de su mejora en el conocimiento del núcleo de los átomos, superconductividad, etcétera, el problema central de la mecánica cuántica es que, no obstante su elegante y poderoso formalismo, fuente de sus éxitos, no tiene, ni de lejos, una interpretación definida. Caso más complejo es el de la mecánica cuántica relativista que debe enfrentar grandes problemas, incluso a nivel formal.

Una primera conclusión de lo anterior es que la base teórica de la mecánica cuántica no está concluida, situación que se trasluce en el famoso comentario de R. Feynman (Premio Nobel) al expresar que "nadie entiende la mecánica cuántica".

El estado de cosas de la mecánica cuántica, por tanto, corresponde al de un paradigma inacabado, del cual resulta sumamente difícil predicar una capacidad explicativa más allá de los terrenos en que su formalismo ha permitido avances a través de sus propios mecanismos de validación experimental.

Un segundo problema consiste en la determinación del sistema físico apto para ser considerado el explanandum de la mecánica cuántica en el terreno de los estados alternativos de consciencia.

Y por último, aun considerando que la mecánica cuántica pudiera predecir el comportamiento de algún sistema físico de índole bioquímico, neurológico, o de cualquier otra clase, en el mismo sentido que se hace en el terreno de la investigación clínica de los estados alternativos de conciencia, resta el complicadísimo problema consistente en justificar la pertinencia del reduccionismo de los procesos subsimbólicos y simbólicos que ocurren en esos estados, al comportamiento mesurable de los sistemas físicos en cuestión. Es decir, que a pesar de su prestigio de universalidad, la física no puede explicarlo todo.

Valga una metáfora tomada de Alberto de la Torre para esclarecer la afirmación anterior: 
Este libro forma parte del acervo de la Biblioteca Juridica Virtual del Instituto de Investigaciones Juridicas de la UNAM

...en física... un observable es una cualidad de la realidad para la cual existe un procedimiento experimental, la medición, cuyo resultado puede ser expresado por un número. Esta definición es suficientemente amplia para abarcar a todos los observables que participan en los sistemas físicos, pero excluye muchas cualidades que en otros contextos pueden ser calificadas como observables. Por ejemplo, algún color en un cuadro de Botticelli es "observable" porque existen formas de caracterizarlo mediante ciertos números, tales como las intensidades y frecuencias de la luz absorbida o reflejada, pero la belleza del "nacimiento de la Primavera" de Botticelli no sería observable. ${ }^{70}$

En ese mismo sentido, aun cuando la física cuántica pudiera explicar y predecir el comportamiento de un sistema físico de carácter bioquímico, con velocidad pequeña y acción cercana a la constante de Planck que tuviera lugar durante un estado alternativo de consciencia, dudosamente podría explicar lo que significa para un paciente haber sanado una herida, o la relación existente entre la imagen de una luna azul claro que se torna violeta antes de dejar de fumar.

En términos de la filosofía de la mente contemporánea, la especulación sobre la utilidad del paradigma cuántico para explicar los estados alternativos de consciencia queda formulada de la siguiente manera: los paradigmas tradicionales se han mostrado incapaces para establecer atribuciones causales entre estados neurofisiológicos y estados mentales. Esto se debe a que, al parecer, en un mismo estado neurofisiológico pueden ocurrir infinidad de estados mentales y a la inversa, varios estados mentales pueden disparar el mismo estado neurofisiológico. Por tanto, la correspondencia entre ambos tipos de estados constituye una especie de variable oculta para las categorías de la mecánica clásica. Dado que la física cuántica constituye un paradigma alternativo que ha dado cuenta de sistemas físicos no deterministas, es razonable suponer que tal vez, una vez acabada, pueda ofrecernos explica-

70 Idem. 
Este libro forma parte del acervo de la Biblioteca Juridica Virtual del Instituto de Investigaciones Juridicas de la UNAM

ciones a los estados alternativos de consciencia, naturalizadas y alejadas de la dicotomía cerebro-mente.

Ante la falta de una teoría científica que permita explicar los fenómenos supervenientes a la actividad neurofisiológica y bioquímica que acontecen durante los estados alternativos de conciencia, no queda otro camino que recurrir a los recursos característicos del pensamiento precientífico, sin por ello ser caprichosamente especulativo, es decir, a la formulación de una teoría conceptual acerca del funcionamiento subsimbólico y simbólico de la enigmática, pero sin duda eficiente, "parte sabia".

La justificación de este abordaje, desde la perspectiva de la filosofía de la ciencia, queda expresada en las siguientes palabras de Bunge:

Las teorías pueden construirse, remodelarse, reconstruirse lógicamente, aplicarse, destruirse y olvidarse. La construcción de una teoría científica es siempre la edificación de un sistema más o menos afinado y consistente de enunciados que unifica, amplía y profundiza ideas, las cuales, en estado preteorético, habían sido más o menos intuitivas, imprecisas, esquemáticas e inconexas. En los comienzos de la ciencia ese estadio preteorético es simplemente el conocimiento ordinario; en disciplinas ya establecidas no puede presentarse sino en campos particulares; siempre hay alguna teoría más o menos afín que es una ayuda en la construcción, ya prestando materiales, ya sugiriendo planteamientos. ${ }^{71}$

Una teoría conceptual no puede ser validada por las reglas correspondientes a las reglas de procesamiento de la información características de algún método experimental, razón por la cual tiene un carácter precientífico.

En el caso que nos ocupa, la construcción conceptual no corresponde, por tanto, a los fenómenos neurológicos o bioquímicos que tienen lugar durante estados alternativos de conciencia, mismos que son objeto de estudio de la hipnosis experimental.

71 Bunge, Mario, La investigación científica, España, Ariel, 1989. 
Este libro forma parte del acervo de la Biblioteca Juridica Virtual del Instituto de Investigaciones Juridicas de la UNAM

Dicha teoría conceptual se ocupa, más bien, de los estados subsimbólicos y simbólicos supervenientes a dichos procesos biológicos que, respecto de aquellos, vendrían a ser subvenientes.

En síntesis, si se considera que el aparataje neurológico y bioquímico constituye el soporte físico de procesamiento simbólico del hombre, el objeto de la teoría anunciada serán los procesos subsimbólicos y simbólicos supervenientes a la operación de dicho soporte. Metafóricamente hablando, la teoría conceptual propuesta sería equivalente a la teoría de la armonía musical que constituye una abstracción sobre la música, constituida por las relaciones entre diferentes "constructos" denominados notas musicales. Dicha abstracción presupone un sistema complejo que parte de la actividad física del instrumento (la fricción del arco sobre las cuerdas del violín), más un ambiente propicio para la propagación de las ondas sonoras, más dichas ondas, más una adecuada actividad fisiológica del oyente que incluye al tímpano, yunque, martillo, estribo, caracol, los nervios que conducen las ondas al cerebro en términos de impulsos eléctricos y la actividad cerebral que los transforma en sonido. El soporte físico de procesamiento simbólico vendría a ser equivalente a los instrumentos musicales, cuyas propiedades pueden ser explicadas por la ciencia de la física, desde la cual es imposible explicar la música.

\section{LA MENTE COMO SISTEMA GENERADOR DE PROGESOS ESTRUCTURANTES (GARAGTERIZACIÓN TEÓRICA-CONCEPTUAL PREGIENTÍFICA)}

En analogía con los sistemas computacionales, tanto de procesamiento secuencial, como paralelo y, atendiendo a sus propiedades neuroquímicas, el cerebro puede ser definido como un sistema físico de procesamiento simbólico (SFPS). Desde el punto de vista de la física, las partículas, masa y energía implicadas en sus procesos, constituyen al menos un sistema físico con sus correspondientes observables, entre los cuales, probablemente, algunos podrían ser 
Este libro forma parte del acervo de la Biblioteca Juridica Virtual del Instituto de Investigaciones Juridicas de la UNAM

objeto de explicación a partir del paradigma de la física cuántica y actualmente lo son desde el de la mecánica clásica.

Desde la perspectiva de la teoría de los sistemas complejos, los procesos ocurridos en ese SFPS pueden ser considerados subvenientes, respecto de un sistema de mayor complejidad que los presupone, pero que es diferente e irreductible a ellos. Dicho sistema superveniente está constituido por constructos u objetos mentales de carácter subsimbólico y simbólico. Algunos de ellos ocurren a nivel inconsciente (en un sentido distinto del freudiano, como se verá más adelante), y otros, soportados en los anteriores, corresponden a la dimensión consciente. Estos objetos constituyen un sistema "holístico" con dinámica propia, el cual puede ser denotado con la expresión: "sistema generador de procesos estructurantes simbólicos" (SGPES). Dicho sistema opera de manera analógica, más que digital en sus niveles subvenientes e incluye, entre otros, procesos de inducción difusa, generalización, distorsión, conectividad entre subobjetos simbólicos, inferencias transitivas progresivas, que comprenden a los clásicos conceptos de conexión, desplazamiento y condensación (proceso constructivo), así como inferencias transitivas retropropagativas (proceso deconstructivo) y proyectivas, etcétera.

Un ejemplo de objeto subsimbólico sería la sensación que surge en un estado alternativo de consciencia que precede al surgimiento de una representación condensatoria que, por su semejanza con las obras de Dalí, podríamos calificar como "surrealista" u "onírica", misma que suele ser el punto de partida del proceso de elaboración psicoterapéutica.

Mediante este sencillo ejemplo es posible ilustrar la actividad realizada por el SGPES: un primer nivel de superveniencia corresponde a la sensación propioceptivamente captada como algo difuso, la cual es el inicio del proceso de elaboración de una segunda superveniencia que correspondería a la representación de corte surrealista.

Los ejemplos de superveniencias simbólicas a nivel consciente abundan y son ampliamente conocidos, entre ellos se encuen- 
Este libro forma parte del acervo de la Biblioteca Juridica Virtual del Instituto de Investigaciones Juridicas de la UNAM

tran las entidades proposicionales, las arborescencias semánticas, los distintos tipos de imágenes mentales isomórficas, tales como son los recuerdos, las representaciones descriptivas, etcétera.

No debe suponerse una separación absoluta entre ambas dimensiones simbólicas, la inconsciente y la consciente, pues, como sucede en el caso de técnicas diversas a las ericksonianas, las representaciones conscientes constituyen el grado último de una elaboración subsimbólica de carácter inconsciente (caso del psicoanálisis o el focusing).

De conformidad con lo anterior, "La mente es considerada como un sistema de manipulación simbólica que tiene su base en la adquisición, manejo y procesamiento de la información". ${ }^{72}$

Por otra parte, las dimensiones simbólica y subsimbólica constituyen una parte del binomio representacional-conductual, "...la conducta es un fenómeno que tiene su origen en la construcción y reconstrucción que se va haciendo del mundo a nivel mental".

A pesar de que el SGPES no puede ser reducido al SFPS, entre ambos existe una interconexión, pues lo que podríamos llamar "asociatividad simbólica" parece estar soportada en el conexionismo neuronal:

Las neuronas poseen la propiedad de agruparse en complejos que tienden a ser reactivados después de su primera interconexión (regla de Hebb).

Los conjuntos o complejos de neuronas (redes neuronales), a su vez, tienden a activarse o conectarse entre sí de manera cooperativa y codependiente, en función del estado global que guarde el sistema en un momento dado (dependencia del contexto).

De esta actividad autoorganizativa del cerebro, superviene la dimensión simbólica referida previamente.

El surgimiento de cada estado superveniente en la dimensión simbólica presupone que los complejos de conexiones neuroasociativas implicadas hayan alcanzado cierto grado de coherencia e integración.

72 Ibidem, p. 30. 
Este libro forma parte del acervo de la Biblioteca Juridica Virtual del Instituto de Investigaciones Juridicas de la UNAM

Dado que los estados mentales no son permanentes, en nuestro interior tiene lugar un cambiante río de acontecimientos mentales momentáneos y recurrentes.

Dicho de otra manera, nuestra mente no es un estado, sino un proceso continuo de estados no controlados por reglas, ni por una unidad de coordinación central, sino por la actividad de la red en su conjunto.

Con autores como Minsky y Papet, asumo que más que una maquinaria funcional, la mente puede ser considerada como una sociedad constituida por múltiples agentes que interactúan en forma autoorganizativa y cooperativa, de cuya acción supervienen estados más complejos o agencias, que a su vez pueden dar lugar a la superveniencia de estructuras superiores correspondientes a los estados globales del sistema, siempre cambiantes.

De conformidad con Minsky, la idea de superveniencia simbólica podría ser explicada mediante la analogía con una institución en la que los diferentes agentes realizan funciones sin tener consciencia de la incidencia de las mismas en las acciones de los demás agentes, pero que, a fin de cuentas, incide en el estilo de funcionamiento de la institución en su conjunto. En otros términos, carecen de metaconsciencia.

En tanto sistema no sólo autoorganizativo, sino también dinámico, la propiedad evolutiva del SGPES puede ser explicada empleando el concepto de "enacción" desarrollado por Francisco Varela, según el cual, los sujetos no estructuran su experiencia con vista a ajustarla a un modelo predefinido de la realidad, sino que, más bien, la realidad de cada individuo es el resultado de las experiencias que va encontrando en el transcurso de su vida, mismas que va integrando mediante un proceso de acoplamiento a las estructuras preexistentes. En este sentido, lejos de limitarse a "pintar" un mundo predefinido, nuestra actividad mental lo construye interiormente "haciendo camino al andar".

Por último, el concepto de enacción no se refiere únicamente a procesos cognitivos, sino que también considera la relación que existe entre esos procesos y nuestra acción en el mundo, 
Este libro forma parte del acervo de la Biblioteca Juridica Virtual del Instituto de Investigaciones Juridicas de la UNAM

el cual, "reacciona" ante nuestras conductas de cierta manera, produciendo nuevas experiencias susceptibles de nuevos acoplamientos estructurales, siempre transitorios y posiblemente recurrentes.

La relación entre la estructura de la experiencia de vida y la manera de percibir, integrar y acoplar en ella lo que acontece en el mundo, gracias a sus propiedades adaptativas, implica procesos no sólo recursivos, sino también redundantes. Esto significa que, a manera de un círculo vicioso, la estructura de la experiencia de vida de cada sujeto determina su forma de percibir el mundo y comportarse en él, y la "reacción del mundo", resultante de dicha interacción, refuerza la percepción del sujeto. Dicho en otras palabras, la experiencia de vida de cada sujeto determina su percepción del mundo, misma que refuerza la estructura desde la que ha sido producida. En este sentido, la adaptatividad estructural del individuo está condicionada (aunque no determinada) por la estructura o estructuras previas (basadas en complejos neuronales cooperativos y codependientes).

\section{Poder explicativo del modelo en la interacción terapéutica}

La tendencia natural en el proceso adaptativo de cada sujeto se orienta hacia la búsqueda del bienestar. Sin embargo, puede suceder que en algún punto del proceso enactivo, el sujeto produzca estructuras o redes de carácter displacentero, que serán robustecidas sin su control consciente debido al carácter autoorganizativo de su aparato cognitivo.

Quizá por razones evolutivas (hay que centrar la atención en lo amenazante para sobrevivir), las estructuras displacenteras (complejos) suelen tener más peso que las placenteras. En este sentido, las primeras funcionan como subredes dominantes y, las segundas, como subredes recesivas.

El trabajo de ayuda psicológica consiste en inducir la disolución de las subredes dominantes displacenteras mediante una modificación de las conexiones neuroasociativas del sujeto 
Este libro forma parte del acervo de la Biblioteca Juridica Virtual del Instituto de Investigaciones Juridicas de la UNAM

que están en la base de los estados subsimbólicos y simbólicos emergentes desde el código simbólico-emotivo privado del individuo.

Si se aplica la segunda ley de la termodinámica, el proceso permite una liberación de energía negativa, para transformarla en energía positiva que debe revertir en una reconfiguración del estado global del sistema, donde el factor dominante sea el bienestar robustecible enactivamente.

Dado que la dinámica del cerebro y del aparato cognitivo en general procede a través de conexiones codependientes, al disolverse algunas de las conexiones, se desestabiliza el estado global del sistema, que comienza a modificarse, autoorganizativamente, a través de un proceso de retropropagación protectiva.

En este punto, debe ser señalada una deficiencia de la teoría de la enacción, en el sentido de que, a partir de ella, pareciera que estamos condenados a ser producto de una autoorganizatividad sin dirección, a seguir el camino que la autoorganizatividad y las estructuras previas indiquen, a hacer camino al andar, pero de forma ciega.

Si ése fuera el caso, poco podríamos hacer por autodirigir la construcción de nuestra experiencia de vida.

Dado que la teoría enactiva no fue pensada como una teoría para la ayuda psicológica, sino para explicar el proceso de la cognición, no requería dar cuenta de este problema, razón por la que se hace indispensable complementarla con el concepto de cerebro como un servomecanismo, es decir, como un sistema cuya autoorganización puede ser orientada hacia un propósito definido: "como una maquinaria que automáticamente persigue fines determinados y dirige su rumbo a un blanco prefijado, o a una meta, mediante el empleo de la retroalimentación de la información que recibe".

A alguien podría parecerle un contrasentido hablar del cerebro como servomecanismo y autoorganizatividad, pero no es el caso. La autoorganizatividad puede comenzar su función a partir de la definición del objetivo a alcanzar, como si dejáramos a un 
Este libro forma parte del acervo de la Biblioteca Juridica Virtual del Instituto de Investigaciones Juridicas de la UNAM

auto, con sistema de inteligencia artificial, elegir la ruta adecuada y conducir hasta el destino que le ha sido definido.

En el caso de los seres humanos, la ayuda psicológica consiste en apoyar a los individuos a identificar el punto de llegada, o, al menos, la ruta de navegación, en ayudar a eliminar las redes displacenteras dominantes para que emerjan las recesivas placenteras, y en dejar el resto a la autoorganizatividad. Dejar todo en manos de lo que algunos llaman la "parte sabia".

\section{Poder explicativo del modelo en la construcción del conocimiento compilado}

Uno de los aspectos más apasionantes de este nuevo paradigma es, sin duda, la explicación de la forma en que se va adquiriendo el conocimiento y consiguientemente, la manera en que vamos construyendo nuestra realidad.

En este sentido, el conocimiento que se va adquiriendo va agrupándose en forma de mapas o redes de información muy bien establecidas, pero, hasta cierto punto, infinitas, ya que éstas dependen de la cantidad y calidad de conocimientos que se vayan acumulando dentro de las mismas.

Los objetos supervenientes en la dimensión simbólica de referencia se organizan por virtud de las propiedades autoorganizativas del propio SGPES. Dichos mapas pueden ser definidos como "la unidad fundamental de la organización cognoscitiva, compuesta de conocimientos y afectos, que crean una reacción, los cuales reflejan la imagen del universo y la cultura subjetiva de la persona". ${ }^{73}$

En síntesis, puede decirse que nuestra mente, al ser un procesador simbólico, organiza y estructura la información que recibe a la manera de mapas de distribución jerarquizada, de los que emergen las representaciones mentales mediante las que construimos la realidad desde la que y con la que interactuamos.

73 Ibidem, p. 15. 
Este libro forma parte del acervo de la Biblioteca Juridica Virtual del Instituto de Investigaciones Juridicas de la UNAM

Esta relación entre la dimensión simbólica y la conductual ha llevado a definir el significado psicológico como:

...la unidad fundamental de la organización cognoscitiva, que está compuesta de elementos afectivos y de conocimientos, que crean un código subjetivo de reacción, los cuales reflejan la imagen del universo y la cultura subjetiva que tiene la persona, puesto que es al mismo tiempo, una unidad natural de representación cognoscitiva y de estimulación para la producción de conducta. ${ }^{74}$

Como es fácil suponer, el modelo expuesto expresa el presupuesto básico del constructivismo, que pone en jaque a muchos de los conceptos centrales de la concepción empirista, como es el caso de la creencia en una realidad objetiva, una verdad absoluta determinable por correspondencia con el mundo externo, el papel constatativo isomórfico de las teorías, etcétera.

A grandes rasgos, este modelo explicativo sirve para comprender la construcción de ambos tipos de conocimiento referidos anteriormente.

En el caso del conocimiento teórico, los constructos obtenidos son el resultado de las reglas de procesamiento de la información (método científico) correspondientes a cada comunidad y son determinados por el paradigma suscrito por sus integrantes.

En el caso del conocimiento heurístico o compilado, juegan un papel fundamental las propiedades adaptativas del SGPES, el cual integra los objetos simbólicos que supervienen y dejan registros en la memoria episódica del sujeto cognoscente, los cuáles constituyen, a su vez, la base para la realización de inducciones difusas que habrán de culminar en la superveniencia de nuevos objetos simbólicos a nivel de la memoria semántica, para que, ante la aparición de datos, situaciones o problemas posteriores y a partir de dichas generalizaciones, tengan lugar las inferencias transitivas que hacen posible la adaptación de esquemas previos a casos nuevos, incrementando, de esa manera, el arsenal de ma-

$74 \quad$ Ibidem, p. 56. 
Este libro forma parte del acervo de la Biblioteca Juridica Virtual del Instituto de Investigaciones Juridicas de la UNAM

pas disponibles en el espacio de búsqueda del sistema para enfrentar nuevos casos.

La propiedad redundante del sistema, así como su carácter servoenactivo, se pone de manifiesto en el funcionamiento retroproyectivo de la actividad judicial, misma que frecuentemente se traduce en profecías autocumplidas que orientan el proceso de estructuración de un caso. Esto significa que, contrariamente a lo que hace suponer la ideología jurídica tradicional, los jueces no deciden desde la neutralidad, sino que, al momento de dictar sentencia, ya han pre-decidido el caso en función de los esquemas o mapas disparados previamente, con base a su conocimiento heurístico.

Como se ha indicado precedentemente, dichos procesos ocurren en los operadores jurídicos del ámbito jurisdiccional a nivel inconsciente y, por tanto, requieren ser objeto de elicitación.

\section{VERSIÓN GONTEMPORÁNEA DEL GONCEPTO DE "PARTE SABIA": EL INCONSCIENTE ADAPTATIVO}

\section{El inconsciente adaptativo en la investigación psicológica de frontera}

En la actualidad, la mayor parte de las investigaciones en psicología presuponen la idea del procesamiento inconsciente:

Times have changed. It is difficult to pick up a psychology journal without some reference to nonconscious processing or related terms such as implicit versus explicit processes, automaticity, or procedural versus declarative knowledge. As research on the limits of conscious awareness has exploded, compelling questions about self-knowledge have begun to be asked. ${ }^{75}$

Uno de los temas de frontera en la investigación psicológica contemporánea versa sobre el llamado "inconsciente adaptativo"

75 Wilson, Timothy, Strangers to Ourselves, Estados Unidos, Harvard University Press, 2002. 
Este libro forma parte del acervo de la Biblioteca Juridica Virtual del Instituto de Investigaciones Juridicas de la UNAM

(IA) que se aleja profundamente del concepto de inconsciente freudiano para construir un modelo explicativo del procesamiento de información que ocurre a nivel biológico, sin control del consciente, de la misma manera que ocurre con el funcionamiento de otros sistemas como el inmunológico, el circulatorio, digestivo, etcétera.

Como todo nuevo paradigma, las investigaciones sobre el inconsciente adaptativo rompen con muchos presupuestos centrales de los paradigmas anteriores. Entre ellos, el que asume que tenemos un control importante de nuestra vida psíquica y procesos intelectuales a través del consciente, pues, si algo están mostrando los múltiples experimentos realizados en distintas universidades es que el consciente tiene una función sumamente modesta en nuestra actividad mental, pues la mayor parte de la misma corre a cargo del IA.

Entre las propiedades del inconsciente adaptativo se afirma que es imposible tener acceso al mismo a partir de la mera introspección.

La idea básica es que, así como el conocimiento de nuestro sistema inmunológico hubiera sido imposible mediante introspección y pudo tener lugar gracias a la generación de modelos obtenidos a través del método científico, es necesario modelar el funcionamiento de dicho IA.

\section{El modelo del SGPES interpretado desde la descripción del inconsciente adaptativo}

Desafortunadamente, por razones de espacio, es imposible sintetizar en este trabajo las diferentes aportaciones efectuadas sobre el tema, a efecto de justificar en qué sentido el modelo referido puede considerarse una abstracción conceptual válida.

Lo que a continuación se presenta constituye una abstracción conceptual que puede ser confrontada con la descripción del inconsciente adaptativo realizada en el paradigmático trabajo de Wilson. Como se verá, el ajuste de esta abstracción con el modelo del SGPES es altamente plausible. 
Este libro forma parte del acervo de la Biblioteca Juridica Virtual del Instituto de Investigaciones Juridicas de la UNAM

Abstracción teórica sobre la descripción funcional del inconsciente adaptativo:

\section{A. Propiedades sistémicas}

1) Abierto. Produce intercambios con el mundo interno y externo del sujeto.

Le supervienen estructuras o patrones poco flexibles.

2) Dinámico. Es relativamente sensible a los cambios del entorno, mismos que monitorea en el aquí y ahora online.

3) Evolutivo. Las estructuras son modificables en función de sus propiedades adaptativas.

4) Autoorganizativo (subveniente)

A) Conexionista. Es sensible a las covarianzas de la información externa, misma que estructura y organiza mediante procesos de integración. En él radican los proceso de transferencia, que implican subprocesos de asociación, condensación y desplazamiento.

B) Enactivo. Los estados posteriores son determinados en función de las estructuras precedentes. La evolución se realiza integrando cambios en el medio ambiente, surgidos del actuar en el mundo por parte del sujeto.

G) Retroproyectivo. La evolución enactiva implica la posibilidad de la adaptación de estructuras del pasado a situaciones presentes, en función de expectativas proyectadas a futuro. También puede implicar cambios de las estructuras pasadas con base en acontecimientos presentes, lo suficientemente fuertes para modificar los esquemas preexistentes. Es la base de las profecías autocumplidas. La modificación estructural no implica necesariamente el cambio de una estructura considerada como un objeto compacto, más bien, por retropropagación asociativa, en función de los pesos de los elementos que se modifican. 
Este libro forma parte del acervo de la Biblioteca Juridica Virtual del Instituto de Investigaciones Juridicas de la UNAM

D) Codependiente. Una modificación en algún elemento de una estructura incide en la reconfiguración del total de la misma.

E) Teleológico (servomecanismo). Se orienta a objetivos específicos independientemente de los conscientes.

F) Recursivo. Es reforzado por la interacción que produce sobre sí mismo a partir de la codificación de información proveniente del exterior.

\section{B. Operación}

1) Abierto. Procesa más de once millones de inputs por segundo, mientras el consciente registra sólo cuarenta.

Controla los procesos de atención selectiva monitoreando aquella información a la que el consciente ha dejado de prestar atención.

2) Autoorganizatividad. Es responsable del aprendizaje implícito.

\section{El inconsciente adaptativo sujeto a experimentación}

En trabajos experimentales se ha mostrado el comportamiento conforme a reglas que nunca fueron explicitadas (predicción de la posición de "x" en la pantalla de la computadora).

Un ejemplo de retroproyectividad opera cuando, al conocer a algún desconocido, se le asimila a una persona conocida previamente y se produce transferencia de actitudes.

En condiciones experimentales se ha mostrado la transferencia de palabras hostiles a rostros con expresividad neutra expuestos de manera posterior inmediata.

El papel de las emociones en la toma de decisiones, rompiendo el mito de la fría racionalidad, ha sido probado por Damasio en el caso de pacientes con problemas emocionales que se ven imposibilitados para tomar una decisión. 
Este libro forma parte del acervo de la Biblioteca Juridica Virtual del Instituto de Investigaciones Juridicas de la UNAM

El carácter teleológico, diverso del consciente, se ha mostrado en experimentos en los cuales, los sujetos de experimentación se conducen en función de la atracción sexual hacia el género opuesto, aunque reporten hacerlo por razones diferentes.

El funcionamiento de los patrones se ha mostrado experimentalmente en la identificación de ciertas categorías de accesibilidad crónica determinantes de las expectativas que un sujeto espera encontrar en otros al conocerlos y codificarlo en función de su satisfacción o no. De igual manera, se han mostrado experimentalmente prejuicios por discriminación racial (presentación del experimento como si se tratara de estudiar la capacidad para realizar dos tareas a la vez, exposición de rostros y solicitud de presionar los botones correspondientes a ciertas palabras que resultan ser peyorativas cuando la imagen es de un negro).

Las explicaciones conscientes sobre lo que acontece a los sujetos a partir de las operaciones del inconsciente adaptativo son totalmente independientes de estos procesos.

Ejemplos: en laboratorio se ha mostrado que pacientes con síndrome de Korsakoff explican, de manera coherente, sus cambios de percepción derivados de estados amnésicos y falta de sentido de continuidad; también, se ha mostrado la forma en que, sujetos con cerebro escindido, explican, conforme al hemisferio izquierdo, lo realizado por el derecho.

En condiciones experimentales, se ha mostrado que la gente atribuye explicaciones a sus conductas que no tienen nada que ver con la forma en que el inconsciente las disparó. Asimismo, se ha mostrado que la construcción de estas explicaciones se basa en creencias socialmente compartidas o esquemas privados, derivados de la experiencia personal.

De igual forma, se ha mostrado que aun cuando la gente explique y justifique su conducta en términos de pensamientos conscientes, el disparador suele ser inconsciente (el caso de la solicitud de comida saludable en un expendio de comida chatarra, después de haber encontrado a alguien que refiera los beneficios de una dieta que ha estado llevando). 
Este libro forma parte del acervo de la Biblioteca Juridica Virtual del Instituto de Investigaciones Juridicas de la UNAM

Un experimento interesante muestra que, aunque la gente se declare no racista, inconscientemente se comporta con base en perjuicios automatizados.

\section{El inconsciente adaptativo en diferentes contextos y el concepto de "parte sabia"}

En su trabajo interesante divulgativo: Inteligencia Intui-tiva,${ }^{76}$ Malcolm Gladwell proporciona innumerables ejemplos de los procesos a cargo del inconsciente adaptativo que satisfacen las propiedades atribuidas al modelo SGPES. Entre ellos se pueden citar los siguientes:

1) En la vida cotidiana: el inconsciente adaptativo es generador de actitudes de discriminación racial demostradas experimentalmente, en contra de la actitud igualitaria declarada explícitamente por los participantes en el experimento. De igual forma el inconsciente actúa en contra de las mujeres en el terreno de la música. De la misma manera se ha constatado que la identificación de una sonrisa falsa obedece a la percepción inconsciente de incoherencias en la totalidad de las expresiones faciales, imperceptibles por el consciente.

2) En los deportes: se ha mostrado que el sentido de "cancha" o de totalidad, característico de los jugadores de basquetbol, quienes atienden infinidad de variables a la vez durante un juego, es controlado por el IA. Asimismo, sucede con los bateadores de beisbol, quienes nunca "ven" realmente la pelota, debido a su velocidad.

3) En operaciones militares: se han documentado casos durante la segunda guerra, en los cuales, los espías encargados de interceptar mensajes en código morse de los enemigos aprendieron a reconocer a los emisores de los mismos, por

76 Gladwell, Malcom, Inteligencia intuitiva, Taurus, 2006. 
Este libro forma parte del acervo de la Biblioteca Juridica Virtual del Instituto de Investigaciones Juridicas de la UNAM

las sutiles variaciones en el estilo de pulsar el aparato emisor del mensaje y, por tanto, identificar hacia dónde se habían movido determinadas unidades en función de la procedencia del emisor.

4) En el laboratorio: se ha mostrado que las personas sujetas a un experimento basado en un juego que hará perder mucho, que requerirá dos paquetes de cartas y del cual no se habrán explicitado las reglas del juego, aprenden a evitar intuitivamente a las cartas perdedoras. Sin haber explicado el patrón de aparición de una " $x$ " en una pantalla de computadora, los sujetos al experimento aprenden a anticipar su aparición a partir de la identificación inconsciente del patrón implícito. Sujetos sometidos a un texto entremezclado que contiene términos alusivos a la vejez salen del consultorio reproduciendo el comportamiento corporal de un anciano.

5) Entre expertos: se ha mostrado que los catadores de vinos o perfumes aprenden a realizar sus clasificaciones sin realizar procesos conscientes de razonamiento. Se ha mostrado cómo, a pesar de todas las pruebas de autenticidad previas a la adquisición de obras de arte por parte de un célebre museo, un hombre, con gran experiencia y sin pruebas científicas, identificó la falsificación de una obra a punto de ser adquirida. Asimismo, se ha mostrado cómo psicólogos especialistas en parejas pueden predecir, con un altísimo porcentaje de éxito, quiénes van a constituir matrimonios estables o no, con sólo observar la "danza" ocurrida en sus interacciones y en su proxémica durante la primera entrevista.

Como queda de manifiesto, este tipo de procesos son de la misma clase que los referidos a la "parte sabia" en el terreno de la terapia eicksoniana, lo cual lleva a concluir que Milton Erickson y Teresa Robles se pueden considerar pioneros en el conocimiento de este novedoso objeto de investigación. 
Este libro forma parte del acervo de la Biblioteca Juridica Virtual del Instituto de Investigaciones Juridicas de la UNAM

Por otra parte, permite mostrar que en la actualidad, esa misteriosa y fundamental parte de nuestra vida interior, generadora de lo que consideramos que hay en el exterior por no ser conscientes de que lo hemos producido dentro, puede ser estudiada conforme a los cánones científico-experimentales.

Además, es el inconsciente adaptativo el responsable, no sólo de la estructuración de nuestra experiencia de vida y las teorías implícitas que asumimos como reales para orientarnos en el mundo, sino también de la asimilación del conocimiento académico y de la compilación del conocimiento heurístico derivado de la experiencia personal $i$. e., de las teorías implícitas formadas a lo largo del ejercicio profesional por cualquier experto en cualquier disciplina, entre ellos, los jueces.

A partir de las referencias precedentes, se presenta una cuestión interesante relativa a la determinación de diferentes clases de inconscientes adaptativos o si, por otra parte, es uno solo con una multiplicidad funcional.

Para Wilson, el inconsciente adaptativo está integrado por una multiplicidad de sistemas encargados de diferentes funciones: "As already noted it is a bit of misnomer to speak of the adaptive unconscious, as there are a collection of modules that perform independent functions outside of conscious view" ${ }^{77}$

Desde esta perspectiva y en relación directa con las técnicas ericksonianas, la llamada "parte sabia" puede ser considerada como uno de dichos módulos.

$\mathrm{Al}$ respecto, refiere Teresa Robles aludiendo a Erickson: "Para Milton H. Erickson nuestra mente inconsciente era como una parte sabia porque ahí estaban las experiencias de nuestros primeros años de vida que, para él, constituyen aprendizajes estructurantes que nos sirven de base para resolver cualquier situación que la vida nos presente". ${ }^{78}$

77 Wilson, Timothy, Strangers to Ourselves, Estados Unidos, Harvard University Press, 2002, p. 59.

${ }^{78}$ Corzo, Iris, Entrevista a Teresa Robles. Un nuevo estilo de hacer terapia, México, Alom Editores, 2001, p. 56. 
Este libro forma parte del acervo de la Biblioteca Juridica Virtual del Instituto de Investigaciones Juridicas de la UNAM

Desde un marco conceptual diferente, Teresa Robles concibe a la parte sabia como una especie de estructura fractal de la totalidad del universo en el que se encuentra la información de todos los tiempos y a la que cada uno de nosotros puede tener acceso gracias a dicha parte sabia. ${ }^{79}$

A pesar de las raíces jungianas basadas en una metáfora de la física cuántica, debe resaltarse la función característica de este módulo del inconsciente adaptativo, encargado de resolver problemas psíquicos y desajustes emocionales derivados de nuestras experiencias de vida. Ello haría suponer que las técnicas ericksonianas son útiles únicamente en el trabajo terapéutico. Sin embargo, como se verá más adelante, han resultado sumamente eficaces en la realización de experimentos sobre la elicitación del conocimiento judicial.

\section{Inconsciente adaptativo y constructivismo judicial}

En algún sentido y siguiendo a Vigotsky, se puede afirmar que la mente es un producto que se construye socialmente. ${ }^{80}$

Esto significa que el hombre puede ser considerado como una especie de agente inmerso en un medio con el que intercambia información constantemente, del que recibe los estímulos que son procesados por el inconsciente adaptativo de manera autoorganizativa y sin un estricto control consciente, en los términos apuntados previamente.

Esta afirmación, en principio realizada para la sociedad en su conjunto, es válida también para contextos más restringidos y para subuniversos simbólicos determinados. Uno de ellos corresponde al terreno de la vida profesional en que los jueces se encuentran inmersos y también se socializan.

79 Robles, Teresa, Manual de grupo de crecimiento, México, Aloim Editores, 2003, p. 22.

80 Véase García González, Enrique, Vigotsky, La construcción histórica de la psique, Trillas, 2000; Vygotzky, Lev, Thought and Language, MIT Press, 1986, p. 344; Vygotsky, Lev, Mind in Society: Development of Higher Psychological Processes, Harvard University Press, 2006, p. 159. 
Este libro forma parte del acervo de la Biblioteca Juridica Virtual del Instituto de Investigaciones Juridicas de la UNAM

Consecuentemente, el simple interaccionismo simbólico ocurrido en la práctica jurisdiccional cotidiana produce esquemas determinantes del comportamiento judicial, mediante lo que se ha llamado "aprendizaje implícito". Gracias a él, se construye el conocimiento experto que permite resolver adecuadamente casos complejos, como no lo podría hacer un principiante, pero también puede ser la matriz generadora de graves disfunciones.

Tomando como punto de partida una investigación empírica realizada por Luis Pásara acerca de la manera en que deciden los jueces penales del Distrito Federal, ${ }^{81}$ se puede realizar la siguiente reconstrucción en términos constructivistas:

1) Los jueces presentan esquemas sumamente rígidos, lo que se traduce en una sospechosa homogeneidad en las sentencias en materia penal.

2) Se observa un fenómeno de refracción cognoscitiva por parte de los jueces, al no integrar ni procesar más pruebas que las testimoniales y declaraciones. De igual manera sucede con la falta de integración de insumos cognitivos provenientes de la jurisprudencia, doctrina $y$ principios generales del derecho, necesarios para generar constructos normativos. Otra muestra de rigidez de los esquemas se presenta en el peso atribuido al principio de inmediatez.

3) El carácter retroproyectivo de los esquemas judiciales se manifiesta en una profecía autocumplida consistente en la predeterminación de la sentencia por el auto de término constitucional, producido por el Ministerio Público.

4) Los procesos de atención selectiva deficientes están presentes en la falta de consideración del estado de tentativa de los delitos cometidos, así como en el tratamiento deficiente de los elementos del cuerpo del delito y presunta responsabilidad.

81 Pásara, Luis, Cómo sentencian los jueces del Distrito Federal en materia penal, México, UNAM, Instituto de Investigaciones Jurídicas, 2006. 
Este libro forma parte del acervo de la Biblioteca Juridica Virtual del Instituto de Investigaciones Juridicas de la UNAM

5) La falta de argumentación detallada y la práctica de "cortar y pegar" casi la totalidad del expediente son muestra de la forma en que los jueces presentan supuestas justificaciones de su decisión, que nada tienen que ver con los procesos que efectivamente ha disparado su narrativa.

En síntesis, los jueces deciden con base en procesos y esquemas generados por el inconsciente adaptativo, dentro de un contexto de aprendizaje implícito.

Las consecuencias de lo anterior son sumamente importantes, pues muestran cómo la práctica profesional constituye la matriz comunicativa a partir de la cual el inconsciente adaptativo genera las estructuras necesarias para poder participar y manipular un mundo social, también autoorganizativamente, generando frecuentemente un estado disfuncional. Es aquí donde se encuentra la clave de las prácticas corruptas de muchas instituciones jurídicas, de la manera en que generar buenas leyes no es sino un simple presupuesto para que pueda emerger la realidad social esperada por la sociedad, donde radica la muestra de que, a pesar de nuestra teleología conscientemente elaborada y subyacente al sistema normativo, la dinámica de la generación de la realidad social toma su camino por cuenta propia, de modos no siempre deseados por el "poder detrás de la silla": el inconsciente adaptativo que actúa detrás de nuestra racionalidad consciente.

Lo anterior no debe satanizar el papel del inconsciente, pues él también es el responsable de la generación de los esquemas a partir de los que actúan funcionarios ejemplares, cuyas estrategias de aplicación del derecho merecen ser consultadas y aprendidas por otros funcionarios con menor grado de pericia. Son estos esquemas los que habrán de ser modelados en el sistema inteligente de nuestro proyecto y también, habrán de configurar los procesos mentales del inconsciente adaptativo de los usuarios del sistema, a través de la simple interacción con el mismo. 
Este libro forma parte del acervo de la Biblioteca Juridica Virtual del Instituto de Investigaciones Juridicas de la UNAM

El problema que resta por afrontar es, ¿cómo obtener dichos esquemas, sobre todo si han sido generados y almacenados por el IA, en donde, se sostiene, no es posible tener acceso consciente? 
Este libro forma parte del acervo de la Biblioteca Juridica Virtual del Instituto de Investigaciones Juridicas de la UNAM http://www.juridicas.unam.mx

Libro completo en

http://biblio.juridicas.unam.mx/bjv

https://goo.gl/6JeUWd 
Este libro forma parte del acervo de la Biblioteca Juridica Virtual del Instituto de Investigaciones Juridicas de la UNAM http://www.juridicas.unam.mx

\section{GAPÍtulo TERGERO METODOLOGÍA}

Técnicas ericksonianas y elicitación del conocimiento judicial en la inteligencia artificial aplicada al derecho

\section{TÉGNICAS ERIGKSONIANAS: LLAVES PARA ACGEDER AL INCONSCIENTE ADAPTATIVO}

Como se indicó previamente, la elicitación del conocimiento constituye uno de los problemas centrales en materia de psicología educativa, así como en el terreno de la inteligencia artificial.

El problema ha sido abordado con técnicas más o menos convencionales, tales como la realización de "entrevistas, cuestionarios, juegos de rol, simulaciones y observaciones de la vida real del experto en su contexto".

Sin embargo, la nota característica de estas investigaciones es que el modelo sobre lo que el experto realiza es elaborado a partir de las reglas de procesamiento de la información del propio elicitador, y no mediante una metaestructuración lograda por el propio experto.

A excepción de algunos intentos realizados en el terreno de la PNL por parte de Dilts, ${ }^{82}$ poco se ha realizado desde paradigmas constructivistas sobre la elicitación del conocimiento experto.

82 Véase tres obras de Dilts, Robert, Modeling with NLP, Estados Unidos, Meta Publications, 1998; Changing Belief Systems with NLP, Estados Unidos, Meta Publications, 1990; Encyclopedia of Systemic Neuro-Linguistic-Programming and NLP New Coding, Estados Unidos, NLP University Press, 2000. 
Este libro forma parte del acervo de la Biblioteca Juridica Virtual del Instituto de Investigaciones Juridicas de la UNAM

Es en este punto donde adquiere su justificación última esta investigación, pues su objetivo central consiste en mostrar la utilidad de las técnicas ericksonianas para poder lograr que los poseedores de las teorías implícitas correspondientes al conocimiento compilado, en este caso, los jueces, puedan acceder a las estructuras de su propio inconsciente adaptativo.

Cabe recordar que una de las tesis centrales de los estudiosos del inconsciente adaptativo es que no es posible tener acceso consciente a él.

Sin embargo, incluso el propio Wilson, uno de los más influyentes estudiosos del IA, admite que:

When patients are given suggestions during surgery that they will recover quickly, they subsequently spend less time in the hospital than patients not given the suggestions, despite having no conscious memory of what was said while they were under anesthesia. $^{83}$

Este simple comentario abre la puerta para relativizar la aseveración sobre la inaccesibilidad al inconsciente adaptativo: $\mathrm{Si}$ bien es cierto que no es posible tener acceso al inconsciente adaptativo estando en el consciente, ello no significa que no se pueda acceder al inconsciente a través de estados alternativos de consciencia activados desde el consciente.

Este fenómeno, quizá enigmático para los estudiosos del IA, no lo es en la práctica ericksoniana donde la constatación de dicho acceso y sus resultados son completamente innegables.

Con la finalidad de obtener cierto grado de validación a estas conjeturas teóricas y con el objeto de vencer problemas reales, se procedió a realizar un pequeño taller con técnicas ericksonianas para fomentar la "apertura" del inconsciente adaptativo en el que radican las teorías implícitas de los jueces que colaboran en el proyecto.

83 Wilson, Timothy, op. cit. 
Este libro forma parte del acervo de la Biblioteca Juridica Virtual del Instituto de Investigaciones Juridicas de la UNAM

\section{Dichos problemas eran básicamente dos:}

1) Una desconfianza inicial a proporcionar información acerca del modo de resolver jurisdiccionalmente.

Ello puede constatarse en el siguiente pasaje tomado de un estudio de grupos focales realizado por la psicóloga cognitiva Estela del Valle al inicio de la investigación:

En forma consistente, se observa que el grupo de proyectistas desplaza sus preocupaciones hacia las condiciones sociales y económicas de los usuarios del sistema judicial, reduce notablemente la cantidad y pertinencia de sus participaciones, se "alinea" detrás de las preocupaciones externadas por el grupo de jueces en materia de las perspectivas de transformación, profesionalización y eventual reducción de la plantilla de secretarios. Al parecer se produce un efecto de victimización, negación y desplazamiento de la defensa hacia "voceros" más calificados... en el contexto de la entrevista, se reporta que antes de iniciar el segundo segmento de la entrevista, el grupo solicitó información sobre la confidencialidad y el uso de la investigación. Al mismo tiempo, externaron su preocupación por las posibles implicaciones laborales y políticas de su participación en la entrevista y en la investigación. El incidente se presentó como una forma de reacción concertada (pues el intercambio se escenificó como la posición del grupo a través de algunos "voceros": los operadores con mayor nivel de autoridad institucional del tribunal), y desplazada (pues en el intercambio requerían condiciones de seguridad para el contenido de sus respuestas y, más adelante, expresaron haber sentido que "hablaron demasiado" en la primera sesión de la entrevista. ${ }^{84}$

2) Las respuestas académicas de los jueces acerca de su propia actividad. Esto significa que, en contra de nuestras in-

84 Valle Guerrero, Estela del, "Estudio de grupos focales en el Tribunal Superior de Justicia del Estado de Tabasco. Proyecto Conacyt 42163-S", estudio presentado como parte de los productos académicos correspondientes al segundo reporte técnico del proyecto Conacyt 42163-S "Sistemas expertos para la ayuda a la decisión judicial". 
Este libro forma parte del acervo de la Biblioteca Juridica Virtual del Instituto de Investigaciones Juridicas de la UNAM http://www.juridicas.unam.mx

tuiciones iniciales, al preguntar a los jueces acerca de la manera de realizar su función como juzgadores, no obteníamos respuesta de juzgadores, sino de un profesor de facultad. Es decir, los jueces contestaban a una pregunta sobre sus teorías implícitas y conocimiento compilado con conocimiento académico. Ello significaba una convalidación de la falta de conocimiento consciente del conocimiento a elicitar. 
Este libro forma parte del acervo de la Biblioteca Juridica Virtual del Instituto de Investigaciones Juridicas de la UNAM

\section{CAPÍtulo GUARTO}

\section{RESULTADOS}

\section{CAMBIOS POSTERIORES A LA INDUCGIÓN}

Los participantes en el taller expresaron diversas representaciones subjetivas correspondientes al proceso de abrir el conocimiento inconsciente y compartirlo con jueces con menor grado de pericia.

En términos de dinámica grupal, se percibió una notoria mejoría en la integración e involucramiento en el proyecto, mismo que se tomó como si fuera de ellos.

Durante varios meses se ha seguido trabajando con los jueces y las respuestas académicas se han dejado de lado, para pasar a proporcionar conocimiento heurístico. Debe señalarse que la base teórica del proyecto, expuesta en congresos internacionales, lejos de ser una ocurrencia teórica especulativa subjetiva acerca de lo que pasa en el interior de los jueces, es el resultado de un proceso de retroalimentación con los propios jueces que sigue los siguientes pasos: recopilación de datos acerca de cómo los funcionarios judiciales procesan la información constitutiva de sus casos, estructuración teórico-conceptual por mi parte, exposición y validación por parte de los propios jueces o, en su caso, sugerencia de ajustes al marco teórico que aspira a modelarlos.

El éxito teórico de la investigación se atribuye a la construcción de una teoría o modelo sobre el procesamiento jurisdiccional que, a diferencia de lo que ocurre con la teoría tradicional, evita exponer la forma en que el teórico cree que los jueces razonan (y si no lo hacen como su teoría postula... ipeor para los jueces!). 
Este libro forma parte del acervo de la Biblioteca Juridica Virtual del Instituto de Investigaciones Juridicas de la UNAM

Entre los resultados de la investigación debe resaltarse que los operadores jurídicos han roto con muchos de los presupuestos del paradigma jurídico tradicional y han encontrado y admitido cosas tales como que no resuelven aplicando artículos de las leyes, sino que ellos mismos construyen las normas a partir de las cuales deciden; que las sentencias constituyen una forma de presentación acorde con la ideología dominante, pero que es el resultado de una predecisión; que no resuelven sobre hechos sociales, sino sobre la base de representaciones mentales, de un constructo generado por ellos mismos (a lo cual he dado en llamar "modalidad de instanciación normativa"), y un largo etcétera que no es posible explicitar aquí.

\section{RESERVAS SOBRE LA VERIFICACIÓN EXPERIMENTAL DE LOS RESULTADOS}

Dadas las condiciones bajo las que tuvo que ser efectuada la investigación, la cautela de la profesión judicial aludida previamente, los grandes riesgos derivados de los prejuicios radicados en las representaciones sociales acerca de la hipnosis, que podrían responsabilizar al inductor de cambios en las decisiones judiciales alejados del estilo ortodoxo, etcétera, no fue posible verificar la atribución causal entre el taller y los resultados obtenidos. Por tanto, no queda más que aceptar por vía de conjetura que si un comportamiento del mundo fue modificado después de un evento específico, tenemos buenas razones para suponer que dicho evento, si bien pudo no haber sido la única variable responsable del cambio, al menos puede ser considerada una de ellas.

Desde luego, hubiera sido ideal realizar estudios empleando las modernas técnicas de neuroimagen, para verificar cambios funcionales concomitantes a los procesos simbólicos que estaban ocurriendo durante el estado alternativo de consciencia que antecedió los cambios conductuales de los jueces.

Ello queda pendiente, sin duda alguna, como un siguiente paso en la continuación de esta línea de investigación. 
Este libro forma parte del acervo de la Biblioteca Juridica Virtual del Instituto de Investigaciones Juridicas de la UNAM

\section{GONGLUSIONES}

1) A pesar de que entre los dominios de interés de Milton Erickson se encontró el derecho, sus estudios versaron fundamentalmente en el terreno del derecho penal, con énfasis especial en la sociología criminal, pero no se ocupó de mostrar la utilidad de sus técnicas de modo directo en los operadores jurídicos.

2) La crisis epistemológica del empirismo abre las puertas a nuevos problemas de los que se hace cargo la epistemología constructivista, según la cual la realidad es un constructo.

3) El enfoque constructivista constituye el presupuesto epistemológico tanto para las técnicas psicoterapéuticas ericksonianas, como para el constructivismo jurídico que desde hace años estoy desarrollando.

4) Uno de los dominios del constructivismo jurídico lo constituye el análisis y modelado de la forma en que los operadores jurídicos procesan la información al construir realidades jurídicas.

5) Otro dominio del constructivismo jurídico íntimamente vinculado con el anterior es el de la inteligencia artificial aplicada al derecho.

6) La inteligencia artificial aplicada al derecho se ocupa de simular procesos cognitivos y de razonamiento, realizados por los operadores jurídicos, en un programa de computadora y una de sus principales aplicaciones es el desarrollo de sistemas expertos. Un sistema experto es un programa de cómputo que busca simular los procesos de un especialista en cierto dominio. 
Este libro forma parte del acervo de la Biblioteca Juridica Virtual del Instituto de Investigaciones Juridicas de la UNAM

7) Uno de los principales problemas del constructivismo vinculado a la inteligencia artificial aplicada al derecho consiste en la adquisición o elicitación del conocimiento, como paso previo a su representación y modelado en términos de programa de cómputo.

8) En el Instituto de Investigaciones Jurídicas se ha establecido un área de investigación en inteligencia artificial aplicada al derecho donde se desarrolla un sistema experto en materia de pensión alimenticia financiado por Conacyt, que involucra la participación de psicólogos cognitivos, matemáticos, epistemólogos, juristas y operadores jurisdiccionales. Los socios estratégicos son el Tribunal Superior de Justicia de Tabasco y el CGADET de la UNAM.

9) El conocimiento objeto de elicitación es un conocimiento compilado a manera de teorías implícitas.

10) La generación de dichas teorías está a cargo de cierto tipo de inconsciente y sus propiedades autoorganizativas.

11) Existen importantes semejanzas entre la llamada "parte sabia" en el dominio ericksoniano y el llamado inconsciente adaptativo, objeto de investigación experimental y que ha tenido sorprendentes resultados en la investigación psicológica contemporánea.

12) Tanto a Erickson como a Teresa Robles se les puede considerar como pioneros en el descubrimiento y estudio del inconsciente adaptativo, que actualmente puede ser objeto de rigurosa investigación científica.

13) A pesar de las evidencias operativas del inconsciente adaptativo, no existe aún un marco teórico adecuado para poder explicarlo y resulta prematuro sostener que pueda ser estudiado desde la física cuántica por las siguientes razones: el estado inacabado de la física cuántica, sobre todo en lo relativo a la interpretación de su formalismo; la dificultad para identificar cuál sería el o los sistemas físicos objeto de explicación desde ese paradigma y la imposibili- 
Este libro forma parte del acervo de la Biblioteca Juridica Virtual del Instituto de Investigaciones Juridicas de la UNAM

dad de reducir procesos simbólicos a procesos neurofisiológicos.

14) Para la explicación del inconsciente adaptativo, donde ocurren los estados alternativos de consciencia, se proporciona un modelo teórico denominado sistema generador de procesos estructurantes simbólicos, mismo que presupone los procesos neurológicos entendidos como un sistema físico de procesamiento simbólico.

15) El modelo del SGPES proporciona una abstracción adecuada para explicar las operaciones referidas acerca del inconsciente adaptativo.

16) Una de las propiedades predicadas del inconsciente adaptativo es que no es posible tener acceso a él desde el consciente.

17) El acceso al inconsciente adaptativo resulta primordial en la investigación de la elicitación del conocimiento judicial, debido a que es en él donde se genera el conocimiento compilado a manera de teorías implícitas de los jueces, y por el que es almacenado.

18) Las técnicas ericksonianas permiten refutar la afirmación sobre la inaccesibilidad del inconsciente adaptativo, mostrando que es posible acceder no en él, pero sí desde el consciente, activando estados alternativos de consciencia mediante técnicas ericksonianas.

19) A efecto de probar la conjetura anterior se realizó un taller para la elicitación del conocimiento judicial.

20) A pesar de la imposibilidad de realizar una verificación experimental de los resultados empleando técnicas de investigación contemporánea, como es el caso de las diferentes tecnologías de neuroimagen, debido a las condiciones específicas en que se realizó la investigación y la idiosincrasia de la profesión judicial, los resultados observados son sumamente alentadores.

21) La aplicación de técnicas ericksonianas en el ámbito jurídico constituye uno de los futuros dominios de investiga- 
Este libro forma parte del acervo de la Biblioteca Juridica Virtual del Instituto de Investigaciones Juridicas de la UNAM

ción más desafiantes y apasionantes en un futuro próximo, dado el acercamiento entre neurociencias y derecho, cuya gestación interdisciplinaria apenas ha iniciado gracias al Primer Congreso "Law, Mind and Brain" ocurrido en Londres en febrero del presente año, originando así una nueva área de conocimiento que quien suscribe estas líneas propuso dar identidad en dicho evento con el término "Neuroderecho".

Más allá del dominio académico, i. e., ubicándonos en el terreno de las aplicaciones prácticas, la relación entre técnicas ericksonianas y derecho sugiere un horizonte aún insospechado que, de manera inmediata hace que vengan a mi mente los siguientes dominios: victimología; readaptación social; pedagogía jurídica; argumentación jurídica; negociación, arbitraje y conciliación; programas anticorrupción, y un largo etcétera por descubrir.

22) El objetivo central de esta investigación ha sido mostrar que a la grandeza del pensamiento académico ericksoniano en el terreno de la psicoterapia y a su invaluable impacto en la lucha cotidiana contra el sufrimiento humano, hay que agregarles su carácter vanguardista en el nuevo renacimiento que nos está tocando vivir, del cual, el derecho no puede escapar. 
Este libro forma parte del acervo de la Biblioteca Juridica Virtual del Instituto de Investigaciones Juridicas de la UNAM

\section{ANEXO \\ TALLER PARA LA ELICITACIÓN DEL CONOCIMIENTO JUDICIAL}

\section{DESCRIPCIÓN GENERAL}

Durante la sesión se realizaron los siguientes ejercicios:

\section{El juego de los nueve puntos. Creencias limitantes}

Instrucciones. El objetivo consiste en unir todos los puntos sólo trazando cuatro líneas, sin despegar la pluma del papel.

Resultados. La mayoría de los jueces no pudieron resolver el problema. Sus intentos de solución respetaron siempre el perímetro de los puntos, a pesar de que jamás se les indicó hacerlo.

El ejercicio se aplicó con la intención de demostrar que las propuestas de solución que solemos plantear para ciertos problemas están determinadas por los presupuestos de los que partimos. En su mayoría, dichos presupuestos son el resultado de los procesos de aprendizaje en que participamos, por ello es que generalmente son compartidos por los miembros de una comunidad. Sin embargo, al presentarse casos novedosos, los mencionados presupuestos representan, más bien, obstáculos, creencias limitantes que deben ser removidas si han de hallarse respuestas satisfactorias.

En el caso particular, pretender resolver el ejercicio respetando el perímetro de los puntos es una creencia limitante, como también podría serlo el pensar que una computadora no puede ayudarnos en procesos de decisión, o que los jueces sólo se con- 
Este libro forma parte del acervo de la Biblioteca Juridica Virtual del Instituto de Investigaciones Juridicas de la UNAM

cretan a aplicar la ley. Si queremos encontrar nuevas formas de hacer eficientes nuestras instituciones, quizás debamos remover los presupuestos más comunes a efecto de diseñar estrategias atinentes.

\section{Orientando la percepción}

Se les pide a los jueces que digan qué es lo que ven cuando se les muestran ciertas imágenes utilizadas por psicólogos de la gestalt.

Lo interesante es que, con un poco de esfuerzo y luego de dar la instrucción verbal, los jueces pudieron observar lo que no veían en su primer contacto con las imágenes; los que vieron una copa, después pudieron ver otras imágenes.

Este ejercicio se llevó a cabo con la intención de demostrar que los esquemas cognitivos, generados a partir del procesamiento de información preponderantemente lingüística, determinan lo que podemos percibir en el mundo.

En derecho, esta función de los esquemas cognitivos es más evidente. Piénsese, como, en la conducta consistente en privar de la vida a otro, la cual puede interpretarse como el cumplimiento de una obligación (funcionario del Estado), un homicidio, o una acción en legítima defensa. De la misma manera, un mismo documento, por ejemplo, un acta de matrimonio, puede considerarse una prueba relevante para el caso de una acción de alimentos o de una demanda de divorcio.

En este punto se hizo la observación de la importancia de trabajar con los esquemas cognitivos de los expertos, en lugar de hacerlo con la información que procesan: leyes, códigos o estatutos, expedientes, etcétera.

\section{Nuestra habilidad para generar representaciones mentales}

Se pidió a los jueces que pensaran en algo agradable que hubieran hecho el día anterior; en algo agradable que les hubiera gustado hacer; y en algo que les gustaría hacer en el futuro. 
Este libro forma parte del acervo de la Biblioteca Juridica Virtual del Instituto de Investigaciones Juridicas de la UNAM

El ejercicio se llevó a cabo para demostrar que el lenguaje nos hace activar representaciones mentales pasadas, contrafácticas y futuras, ligadas con elementos emotivos. De la misma manera, en la toma de decisiones judiciales, el proceso implica rescatar esquemas del pasado, incorporar elementos de la situación actual, y proyectar un escenario futuro conforme al cual se estructura el subsiguiente flujo de información. Al recuperarse esquemas se rescatan también los elementos emotivos presentes al registrarse la experiencia.

\section{Ejercicio de meditación: contacto con el inconsciente y elicitación del conocimiento de los jueces expertos}

El llamado conocimiento compilado, el cual tiene que ver con procesos o estrategias heurísticas de solución de problemas (aplicación del conocimiento declarativo a casos particulares), pasa al inconsciente y es empleado por el experto de manera casi automática. Por ejemplo, un doctor experimentado no tiene que ir descartando paso a paso cada una de las hipótesis de padecimientos diferentes que pudiera tener un paciente, sino que su diagnóstico procede más o menos automáticamente. Lo mismo le sucede a un conductor experto, quien no tiene que ser consciente de todos los subprocesos que lo llevan a manejar el automóvil con éxito, sino que éstos se disparan en forma esquemática.

El gran problema para el proyecto consiste en cómo lograr tener acceso a ese conocimiento compilado, cómo de construirlo y cómo volverlo a ensamblar en beneficio del sistema.

Se pidió a los jueces que pusieran atención en su respiración para inducir, de manera natural, un estado alternativo de conciencia.

En el momento adecuado, se les pidió visualizar un encuentro entre ellos, como los expertos impartidores de justicia que son ahora, y los recién graduados de la carrera de derecho que fueron alguna vez. De hecho, se les pidió imaginar cómo acudían prin- 
Este libro forma parte del acervo de la Biblioteca Juridica Virtual del Instituto de Investigaciones Juridicas de la UNAM

cipiantes de todo el mundo a dicha reunión, la cual tenía como propósito que entregaran el gran regalo de su sabio consejo.

Se les pidió que visualizaran lo agradecidos que estaban sus versiones más jóvenes de sí mismos y los demás principiantes por el hecho de haber compartido el secreto de su experiencia.

En ese punto, se les pidió que imaginaran a los jurisconsultos de las épocas pasadas y cómo éstos los felicitaban por contribuir, junto con ellos, a lograr la armonía social.

Para finalizar se les pidió que conservaran las sensaciones agradables del ejercicio y que lentamente abrieran sus ojos.

\section{DeSARRollo DeL TALLER}

\section{Creencias limitantes. El ejercicio de los nueve puntos}

Antes que nada, me gustaría que hiciéramos algunas cosas. Un jueguito que aplico en mis clases. No sé si en alguna ocasión ya lo vimos. Entonces, les voy a pedir que en una hoja dibujen nueve puntos formando un cuadrado. Ya que lo hayan hecho, el juego consiste en lo siguiente: hay que tratar de unir los nueve puntos con cuatro líneas rectas, sin separar la pluma o el lápiz del papel, y sin pasar por las rayas que ya trazaron.

Bueno, la idea no es propiamente que resuelvan el jueguito, sino de ver qué podemos aprender de nuestros intentos de resolverlo. Por lo que estoy viendo se repite algo que casi siempre se presenta: están tratando de resolver el problema de tal suerte que el dibujo final respete el perímetro del cuadrado lo cual nunca fue solicitado. 
Este libro forma parte del acervo de la Biblioteca Juridica Virtual del Instituto de Investigaciones Juridicas de la UNAM

¿Qué es lo primero que aprendemos? Que puede ser que todos tengamos las mismas reglas de procesamiento de información y que conforme a ellas nos encontremos con que la manera de afrontar los problemas sea la misma. Entre ustedes no se pusieron de acuerdo para respetar los límites del cuadrado, sin embargo, todos lo hicieron. ¿Qué quiere decir? Que una creencia determinó, como una especie de supuesto, la manera en que ustedes podrían afrontar el problema y probablemente resolverlo. Y determinó secuencias de pensamiento, actitudes, emociones: “¡así no me sale!”, “¡va de nuevo!”; sentimientos de frustración: "no, a mí no me vencen”, etcétera.

¿Qué fue lo que hicimos? Cambiamos la creencia. Y como ésta, tenemos muchas creencias que, en última instancia, son limitantes. Son creencias que establecen una serie de restricciones a muchas cosas que podríamos hacer, y que además, son injustificadas. Una de las cosas que aprenderemos es a romper nuestras creencias limitantes.

Una de estas creencias limitantes puede ser la de creer que no podemos hacer que una computadora nos ayude con procesos de razonamiento. Otra puede ser que lo que hacemos como jueces es únicamente "aplicar la regla". Lo que haremos es empezar a escapar de estas creencias para empezar a ver otro punto de vista, que es en el que estamos trabajando, uno de tipo constructivista donde no solamente hablamos de normas, sino de procesos mentales, y no solamente de consiente, sino que hablamos del inconsciente.

\section{Esquemas y percepción}

Una de las ideas heredadas del empirismo consiste en suponer que, dado que hay un mundo externo objetivo, ante los mismos datos, todos vemos lo mismo. Vamos a revisar ese supuesto: fijense en la figura famosa de los dos rostros enfrentados o una copa, que nos proporciona la psicología de la gestalt. 
Este libro forma parte del acervo de la Biblioteca Juridica Virtual del Instituto de Investigaciones Juridicas de la UNAM http://www.juridicas.unam.mx

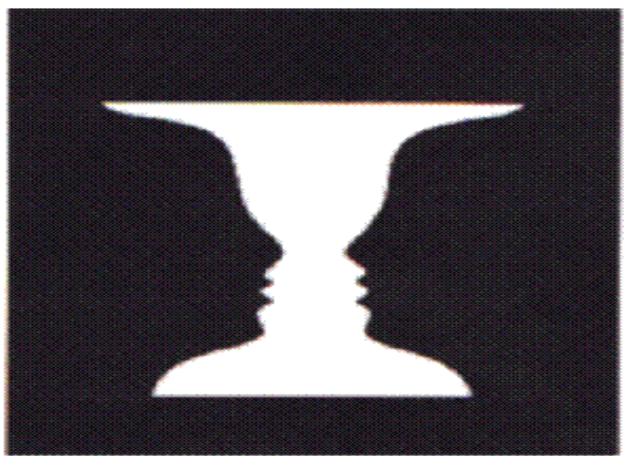

¿Qué más podríamos ver?

Juez 1: La base de una mesa.

Juez 2: Un hongo

Juez 3: Un candelabro

Juez 4: La base de una fuente

Juez 5: Una mujer

Juez 2: Una cascada

Juez 3: Un reloj de arena

Instructor: Y visto de cabeza, tendríamos el cuerpo de un fras-

co con la rosca si tapa y el líquido vertiéndose hacia arriba.

Fíjense que esto se relaciona, de manera muy importante, con la ciencia. Sintéticamente, podríamos parafrasear a Einstein en los siguientes términos: "No es cierto que la realidad determine mis teorías, son mis teorías las que determinan lo que puedo ver como real". Es decir, son mis esquemas los que determinan cómo puedo percibir la realidad.

En el ámbito del derecho, algo se convierte en una prueba relevante por el esquema general desde el cual se considera. Un ejemplo histórico de ello es trabajado por Larry Laudan en el ámbito de la epistemología del derecho: como recuerdan, en la 
Este libro forma parte del acervo de la Biblioteca Juridica Virtual del Instituto de Investigaciones Juridicas de la UNAM

Edad Media se utilizaban las ordalías. Se metía a la gente en aceite hirviendo y se asumía que de no ser culpable, habría una intervención divina que evitaría la muerte del sujeto. Desde luego, nunca hubo tal intervención. Los jueces de aquel entonces eran infalibles.

La decisión por la cual esa prueba dejó de ser relevante no fue ni siquiera epistemológica, fue de carácter teológico. En algún momento se reunieron las autoridades eclesiásticas y dijeron "No debemos seguir asumiendo que podemos pedir a Dios que intervenga como se nos dé la gana", y desde ese momento, dejó de ser relevante como prueba.

¿Qué quiere decir esto? Que incluso las pruebas que consideramos como más contundentes son relevantes por los esquemas desde los que las observamos.

Un expediente se vuelve relevante en función de los esquemas desde los que se le considera. Como vemos, necesitamos de una gran flexibilidad, tanto para remover creencias limitantes, como para estar abiertos a que puede haber distintas percepciones acerca de lo mismo. Puede suceder que en algún momento identifiquemos que haya distintas formas de resolver el mismo caso. Si nos quedamos con la creencia limitante de que sólo puede haber una respuesta correcta, podemos, por definición, determinar como inadecuadas a todas aquellas respuestas posibles que sean diferentes a la nuestra. Conectemos esto con lo que comentábamos acerca de que el cerebro puede organizar la información coherentemente de muchas formas.

Que haya un criterio de decisión no quiere decir que sea intrínsecamente correcto. Puede haber muchas vías diferentes. Y de hecho, si vamos a trabajar con varios jueces, no nos debe sorprender que, en algún momento, unos resuelvan de una manera, y otros, de otra; y que sean plausibles ambas... y otras más. Puede ser que en el sistema tengamos que incluir más de una forma de resolución. 
Este libro forma parte del acervo de la Biblioteca Juridica Virtual del Instituto de Investigaciones Juridicas de la UNAM

\section{Capacidad generativa de representaciones mentales}

- Ahora, les voy a pedir a cada uno de ustedes que recuerden algo que hicieron ayer y que les haya agradado hacerlo.

- Ahora, piensen en algo, también agradable, que les hubiera gustado hacer ayer.

- Ahora, me gustaría que pensaran en algo que les gustaría hacer a futuro.

¿Se dieron cuenta de nuestra capacidad para generar representaciones mentales a voluntad? ¿Qué es lo que distingue una representación mental de lo que hicimos, de otra de lo que nos hubiera gustado hacer, de otra de lo que nos gustaría hacer a futuro? Todas son representaciones mentales. Y fijense cómo están ligadas también con cuestiones emocionales... cómo sintieron estados de bienestar con la simple generación de la imagen.

Con esto trabajamos cuando decidimos: rescatamos esquemas del pasado, los traemos, introducimos lo que está ocurriendo en el caso específico, y lo proyectamos a futuro. Dicha proyección es equivalente a la visión conforme a la cual estructuramos la información para, hasta el final del caso, presentar la estructura argumentativa como si hubiéramos realizado una rigurosa inferencia. Lo orientó nuestra decisión, la manera de estructurar la información del caso fue una preconcepción de hacia dónde decidir.

Estas imágenes que recién formaron corresponden, en buena medida, al hemisferio izquierdo. Todas se refieren al mundo. Las imágenes o representaciones que se generan en el inconsciente son distintas, son parecidas a las que se fabrican en los sueños.

Podemos decir que lo que caracterizaba a Salvador Dalí era precisamente que estaba haciendo representaciones que correspondían al nivel del inconsciente, ahí donde se encuentran las condensaciones. Es ahí donde se encuentra nuestro conocimiento compilado. Es allí a donde intentaremos acceder. 
Este libro forma parte del acervo de la Biblioteca Juridica Virtual del Instituto de Investigaciones Juridicas de la UNAM

\section{Entrando en contacto con la respiración}

Vamos a hacer un ejercicio muy simple que consiste en poner atención a nuestra respiración y entrar en contacto con nuestro inconsciente. Algunos lo llaman "mente inconsciente", otros, "parte sabia", otros, "intuición". Como ustedes quieran llamarle.

Por favor, cierren sus ojos un momento y vamos a hacer un ejercicio que se utiliza en la disciplina de la meditación "zen”, es básico, y consiste sólo en prestar atención a la respiración:

Vamos a prestar atención únicamente al momento en que el aire entra.

- (5 minutos después)... Ahora, prestemos atención sólo a cuando sale el aire.

- (5 minutos después)... Ahora, prestemos atención a todo el recorrido del aire durante nuestra respiración, cómo entra, cómo es que llena nuestros pulmones, cómo sale.

- (5 minutos después)... Ahora, mediante una respiración profunda, pueden volver a abrir sus ojos.

Instructor: ¿Qué tal entrar en contacto con la respiración? Es algo que hacemos siempre, pero que, de repente, cuando tomamos conciencia de ello es algo totalmente diferente. ¿Alguien quiere comentar algo?

Fuez 1: Como que es muy relajante.

Instructor: Claro que es muy relajante. Y fijense que lo que estamos haciendo es entrar en un estado alternativo de conciencia de una forma natural.

Juez 2: ¡Alfa!

Instructor: Entramos en alfa efectivamente. Y esto no tiene nada que ver con cosas extrañas. Cuando, por ejemplo, estamos manejando y de repente llegamos al otro punto y no nos acordamos de lo que pasó en el trayecto, entramos en un estado alternativo de conciencia de forma natural. Cuando estamos absortos 
Este libro forma parte del acervo de la Biblioteca Juridica Virtual del Instituto de Investigaciones Juridicas de la UNAM

escuchando música clásica en un concierto y no nos acordamos de nada más, estamos en estado alternativo de conciencia. Estamos en contacto con nuestro inconsciente. Ahora vamos a tratar de hacer un ejercicio para entrar en contacto con nuestro inconsciente a efecto de empezar a elicitar el conocimiento.

\section{INDUCGIONES}

\section{Primera inducción: encuentro conmigo como juez}

Y ahí donde estás, presta atención a tu respiración e imagínate a ti mismo cuando iniciabas tu carrera judicial y al funcionario judicial que eres hoy, con toda esa experiencia acumulada que te permite resolver cosas que al inicio te hubieran sido muy difíciles o tal vez imposibles de hacer tan bien como lo haces hoy; obsérvalos a uno frente al otro, ve como se reconocen y respetan, y ahora, observa como al lado de ese principiante se van acercando otros principiantes, y yo no sé si sean muchos, o sean pocos, o si sean todos los principiantes de todos los tiempos, y observa como el funcionario judicial actual entrega a esos principiantes la experiencia que él quiera entregarles para que puedan impartir justicia de mejor manera. Y yo no sé cómo es esa entrega, si es en forma de regalo envuelto en cajas de colores, o conectándose con ellos telepáticamente, o entregándoles un chip, o un programa de computadora... sea como sea está bien. Y ahora observa cómo reciben tu experiencia, y cómo te agradecen que la hayas compartido, y como al lado empiezan a aparecer los grandes jurisconsultos de todos los tiempos, y se colocan a tu lado y te felicitan por haber contribuido al igual que ellos a perpetuar el conocimiento del derecho en beneficio de la justicia y la armonía social... Mientras todo esto ocurre, en este proceso de progreso que acaba de iniciar, rescatando los recursos que te permiten decidir cómo lo puedes hacer, con toda esa experiencia acumulada que puedes transmitir a los demás, si todo está bien, disfrutando y conservando todas las sensaciones agradables de este ejercicio, cuando tú lo decidas, haces una respiración profunda y abres los ojos. 
Este libro forma parte del acervo de la Biblioteca Juridica Virtual del Instituto de Investigaciones Juridicas de la UNAM

- ¿Alguien que quiera compartir algo de lo que pasó ahí dentro?

- ¿Se vieron cuando estaban empezando?

- ¿Se vieron ahora, transmitiendo toda esa experiencia?

- ¿De qué manera la transmitían?, en una forma simbólica. Y si no se acuerdan, no se preocupen, todo esto está operando ahí dentro ya.

- ¿Y vieron a los jurisconsultos a su lado?

- (Los jueces asienten)

Lo que vamos a hacer es eso. Así como los jurisconsultos transmitían su experiencia de generación en generación. Así como hoy, los dogmáticos entregan sus conocimientos teóricos a través de los libros a otras generaciones, lo que vamos a hacer es tratar de transmitir esa experiencia personal (pronunciada muy pausadamente y con voz más grave), no la de los libros, a las generaciones que vienen para que puedan compartir lo que nosotros aprendimos. ¿Ok?, ¿todos están bien? Van a ver que van a empezar unos efectos muy padres...

\section{Segunda inducción: intervención para elicitación de conocimiento compilado}

Y ahí donde estás... y ahora, junto con tu respiración entra dentro de ti y viaja hacia tu propio interior hasta llegar ahí donde se encuentran todos los conocimientos adquiridos a lo largo de tu experiencia judicial, los que has utilizado, aprendido y construido a lo largo de tu carrera y deja que tu parte interna, tu mente inconsciente manifieste ese conocimiento... tal vez con un símbolo, representándolo como una biblioteca especializada donde cada uno de los libros contiene tus propios conocimientos como experto, o tal vez como una base de datos, o como una red de información que corre a través de tus redes neuronales, tal vez, incluso, como un color o muchos colores; sea como sea, está bien y ahora observa como ante ti aparece un cofre dorado que contiene la forma de acceder a ese conocimiento, ábrelo y ve lo que 
Este libro forma parte del acervo de la Biblioteca Juridica Virtual del Instituto de Investigaciones Juridicas de la UNAM http://www.juridicas.unam.mx

se encuentra en su interior... tal vez sea un tarjetero con las fichas donde está clasificada la información correspondiente a los libros de tu propia biblioteca, o sea una clave de acceso para tu base de datos, o simplemente la voluntad de hacer que ese conocimiento fluya libremente a través de tus neuronas, cuando tú así lo desees, como tú lo necesites y ahora, usando lo que estaba dentro de tu cofre, accede a esos conocimientos judiciales, observa cómo puedes lograr que surja toda la información que quieres que surja, todos los conocimientos que sabes que tienes y los que no sabes que tienes, pero que sí tienes, los que usas cuando impartes justicia y los que no sabes que usas, pero que sí usas, y observa como fluyen libremente para tu propio beneficio, cuando tú los necesitas, con cada respiración, y ahora, durante un momento disfruta de eso que está ahí.... Y ahora, si todo está bien, deja de momento eso que está ahí y contiene tu conocimiento, conservando contigo esa forma de acceder a él para poderlo usar cuando tú así lo desees, cuando así lo necesites... y ahora... 
Este libro forma parte del acervo de la Biblioteca Juridica Virtual del Instituto de Investigaciones Juridicas de la UNAM

\section{BIBLIOGRAFÍA}

ABIA, Jorge y RoBles, Teresa, Autohipnosis. Aprendiendo a caminar por la vida, México, Alom Editores, 1993.

Aguilera García, Edgar, Inteligencia artificial aplicada al derecho, México, UNAM, Instituto de Investigaciones Jurídicas.

ADARra, Pablo y ZaGGagnini, José Luis, Psicología e inteligencia artificial, Trotta, 1994.

AgUIRRE, Yolanda, La psicoterapia, un proceso en construcción, México, Alom Editores, 2004.

Bunge, Mario, La investigación científica, España, Ariel, 1989.

CÁCERES, Enrique, ¿Qué es el derecho? Iniciación a una concepción lingüística, 2a ed., México, Cámara de Diputados, LVIII Legislatura-UNAM, 2001.

, Lenguaje y derecho. Las normas como sistema de enunciados, México, Cámara de Diputados, LVIII Legislatura-UNAM, 2001.

- Propuesta de manual para la calificación de hechos violatorios de los derechos humanos de la CNDH, México, Comisión Nacional de Derechos Humanos, 2005.

"Psicología y constructivismo jurídico; apuntes para una transición paradigmática interdisciplinaria", en MUÑOZ De Alva Medrano, Marcia (coord.), Violencia social, México, UNAM, Instituto de Investigaciones Jurídicas, 2002.

"Ius-neocognitrón (consideraciones constructivistas sobre la aplicación de las redes neuronales en la reingeniería de las instituciones jurídicas)", en Becerra Ramírez, Manuel y Ovilda Bueno, Rocío, El desarrollo tecnológico y la propiedad intelectual, México, UNAM, Instituto de Investigaciones Jurídicas, 2004. 
Este libro forma parte del acervo de la Biblioteca Juridica Virtual del Instituto de Investigaciones Juridicas de la UNAM Boletín Mexicano de Derecho Comparado, México, nueva serie, año XXXIV, núm. 100, enero-abril de 2001.

, "Las teorías jurídicas como realidades hermenéuticas", Boletín Mexicano de Derecho Comparado, México, nueva serie, año XXXV, núm. 103, enero-abril de 2002.

, "Pasos hacia una teoría jurídica comunicativa", Crítica furídica, México, núm. 16, 1995.

"Lógica jurídica e informática jurídica", Revista de la Fa-

cultad de Derecho de la Universidad Complutense, Madrid, núm. 12, septiembre de 1986.

-, "Reflexiones sobre el status científico de la informática jurídica”, Les Annales de l'IRETIf, Montpellier, núm. 2, 1990.

prensa.

"Constructivismo jurídico sociorrepresentacional", en , "Constructivismo jurídico, verdad y prueba", en prensa.

, "La teoría de la supra-regla. Propuesta de criterio cognitivo para la realización de conexiones normativas no explícitas", en prensa.

Checkland, Peter, Pensamiento de sistemas, práctica de sistemas, México, Noriega Editores, 1993.

CHIU, Chi-yue et al., "Implicit Theories and Conceptions of Morality", fournal of Personality and Social Psychology, vol. 73, núm. 5, 1997.

DiLTs, Robert, Creación de modelos con PNL, España, Urano, 1999.

ERICKSON, Milton, "An Experimental Investigation of the Possible Antisocial Use of Hypnosis", Psychiatry, núm. 2, agosto de 1939.

, "Concerning Present Inadequacies in the Legal Recognition and Handling of the Mentally Ill", Diseases of the Nervous System, vol. VII, núm. 4, abril de 1946.

_- "Criminality in a Group of Male Psychiatric Patients", Mental Hygiene, vol. XXII, núm. 3, julio de 1938. 
Este libro forma parte del acervo de la Biblioteca Juridica Virtual del Instituto de Investigaciones Juridicas de la UNAM

-, "Marriage and Propagation among Criminals", fournal of Social Hygiene, vol. XV. núm. 8, noviembre de 1929. Neurology and Psychiatry, vol. 40, septiembre de 1938.

_- "Some Aspects of Abandonment, Feeblemindedness, and Crime", The American fournal of Sociology, vol. XXXVI, núm. 5, marzo de 1931.

, "The Inhumanity of Ordinary People", International fournal of Psychology, octubre de 1968.

-, El hombre de febrero, Argentina, Amorrortu, 1992.

-, L'Hypnose Thérapeutique, Francia, ESF, 1983.

GarcíA, Rolando (coord.), Piaget y el problema del conocimiento. La epistemología genética y la ciencia contemporánea, Barcelona, Gedisa, 1997.

GLadWELL, Malcolm, Inteligencia intuitiva, Taurus, 2005.

GREENE, Brian, El universo elegante supercuerdas, dimensiones ocultas y la búsqueda de una teoría final, España, Planeta, 2003

Gribirn, John, Física cuántica, España, Planeta, 2004.

Hacyan, Shahen, Relatividad para principiantes, México, Fondo de Cultura Económica, 2005.

KnEE, Raymond, "Implicit Theories of Relationships. Assessment and Prediction of Romantic Relationship Initiation, Coping, and Longevity", Fournal of Personality and Social Psychology, vol. 74, núm. 2, 1998.

LEONDARI, Angelik y Gialamas, Vasilios, "Implicit Theories, Goal Orientations, and Perceived Competence: Impact on Students' Achievement Behavior", Psychology in the Schools, vol. 39(3), 2002, publicado en línea en Wiley InterScience: wrerr.interscience.wiley.com.

MATÉ, José Luis et al., Ingeniería del conocimiento, España, CETTICO, 2000.

MORA, Francisco, ¿Cómo funciona el cerebro?, Madrid, Alianza, 2000. 
Este libro forma parte del acervo de la Biblioteca Juridica Virtual del Instituto de Investigaciones Juridicas de la UNAM http://www.juridicas.unam.mx

PÁSARA, Luis, Cómo sentencian los jueces del Distrito Federal en materia penal, México, UNAM, Instituto de Investigaciones Jurídicas, 2006.

RALPH, Adolphs et al., Emoción y conocimiento, Tusquets, 2002.

Robles, Teresa, Concierto para cuatro cerebros en psicoterapia, México, Alom Editores, 2001.

— Terapia cortada a la medida, México, Instituto Milton H. Erickson de la Ciudad de México, 1994.

TORRe, Alberto Clemente de la, Física cuántica para filo-sofos, México, Fondo de Cultura Económica, 2000.

Wilson, Timothy, Strangers to Ourselves, Estados Unidos, Harvard University Press, 2002.

ZEIG, Jeffrey, Un seminario didáctico con M.H. Erickson, Argentina, Amorrortu, 1998. 